\title{
Current imaging techniques for evaluation of fistula in ano: a review
}

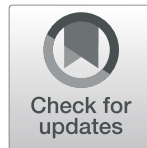

Ashish Sharma ${ }^{1 *} \mathbb{D}$, Priyanka Yadav ${ }^{1}$, Manoranjan Sahu ${ }^{1}$ and Ashish Verma ${ }^{2}$

\begin{abstract}
Background: Fistula in ano is one of the common anorectal disorders which have a tendency to recur specially in complex cases usually due to missed or undetected sepsis at the time of examination or surgery. A correct identification of the primary source of crypt infection along with a complete understanding of the anatomical course of primary and secondary tracks and abscesses is a prerequisite for the successful management of fistula. Preoperative evaluation of fistula in ano using radio-imaging techniques provides a handy insight of fistula anatomy and helps in planning the appropriate treatment strategy. The objective of this article is to review the role of different radio-imaging techniques in the diagnosis and evaluation of fistula in ano along with their advantages and disadvantages over one another.

Main text: A comprehensive literature review was performed searching through the electronic databases as well as the standard textbooks of colorectal surgery. X-rays (plain radiographs and contrast fistulography), computed tomography (CT) scanning, anal endosonography, and magnetic resonance (MR) imaging are the modalities used for preoperative imaging of fistula in ano. Due to low accuracy, X-ray fistulography is not used now for fistula imaging. CT fistulography can be more accurate in cases associated with acute inflammations and abscesses and the fistulas related with inflammatory bowel disease. Anal endosonography and MRI are two of the mostly used and reliable imaging techniques for fistula in ano. Though the use of a 3D technology has improved the accuracy of anal endosonography, MRI is the preferred choice by many. However, various reports have depicted comparable accuracies for both MRI and anal endosonography showing both to be equally sensitive but MRI to be more specific. 3D endoanal ultrasound, on the other hand, is more rapid and can also be used intraoperatively to provide live imaging during surgical exploration.

Conclusion: Complex and recurrent fistula cases should undergo a preoperative imaging to reduce the chances of recurrence. MRI is recommended as the imaging modality of choice for such cases. 3D anal endosonography may however be a good option over MRI owing to its rapidity, availability, and potential of intraoperative assistance during surgery.
\end{abstract}

Keywords: Fistula in ano, X-ray fistulography, CT scanning, anal endosonography, MR imaging

\footnotetext{
* Correspondence: ashish.sharma4@bhu.ac.in

${ }^{1}$ Department of Shalya Tantra, Faculty of Ayurveda, Institute of Medical

Sciences, Banaras Hindu University, Varanasi, India

Full list of author information is available at the end of the article
}

(c) The Author(s). 2020 Open Access This article is licensed under a Creative Commons Attribution 4.0 International License, which permits use, sharing, adaptation, distribution and reproduction in any medium or format, as long as you give appropriate credit to the original author(s) and the source, provide a link to the Creative Commons licence, and indicate if changes were made. The images or other third party material in this article are included in the article's Creative Commons licence, unless indicated otherwise in a credit line to the material. If material is not included in the article's Creative Commons licence and your intended use is not permitted by statutory regulation or exceeds the permitted use, you will need to obtain permission directly from the copyright holder. To view a copy of this licence, visit http://creativecommons.org/licenses/by/4.0/. 


\section{Background}

Fistula in ano is one of the common anorectal disorders which is defined as an abnormal track connecting the anal canal with perineum [1]. Most of the fistulas (approximately $90 \%$ of them) are non-specific and are of cryptoglandular origin which occurs as a result of the infection of anal glands [2]. The rest of the cases are due to a specific etiology like tuberculosis, Crohn's disease, ulcerative colitis, pelvic infections, radiations, carcinomas, and traumas to the anorectal region [3]. Apart from this etiological classification, the anatomical classification of fistula in ano proposed by Sir Allen Parks in 1976 is by far the most followed classification which divides the anal fistula into intersphincteric, transsphincteric, suprasphincteric, and extrasphincteric variety [4] (Fig. 1). However, it is a common practice to categorize fistula in ano into simple and complex varieties which are more practically useful in planning the management strategy for the fistula variety presented. By definition, simple fistulas may be classified as the low transsphincteric or low intersphincteric variety that cross less than $30 \%$ of the external sphincter, has one external opening, and has no evidence of any associated abscess or rectovaginal communication or anorectal strictures. The complex fistulas are fistulas of high-type (high intersphincteric or high transsphincteric) that cross more than $30 \%$ of the external sphincter with or without a high-blind track, suprasphincteric and extrasphincteric fistulas, recurrent fistulas, horseshoe fistulas, fistulas with multiple external openings, fistulas associated with abscesses, active inflammatory bowel disease, chronic diarrhea, rectovaginal communications, anorectal strictures, preexisting fecal incontinence, radiation, or carcinomas. In addition, owing to the attenuated nature of anterior sphincter complex, anterior transsphincteric fistula in females, even of low type, is usually considered as complex [5-7]. For successful management of fistula, it is quite important to delineate its complete anatomy which includes the correct identification of internal opening, the primary site of cryptoglandular infection, and the course of the primary track and of secondary tracks or abscesses if any. Failure of this may result in recurrence. In cases of simple fistulas, this delineation is possible usually with a careful digital rectal examination (preferably bi-digital). However, a problem arises in cases of recurrent and complex fistula. A fistula which seems complex on physical examination (including digital rectal examination) should be evaluated with radiodiagnostic techniques as per standard guidelines [8]. Over the past decades, the radio-imaging for fistula in ano has leapt through many phases of development with newer modalities or improved techniques taking over the previous ones with an upper hand in one or other dimension. The objective of this article is to review the role of different radio-imaging techniques in the diagnosis and evaluation of fistula in ano along with their advantages and disadvantages over one another. A comprehensive literature review was performed searching through electronic databases as well as the standard textbooks of colorectal

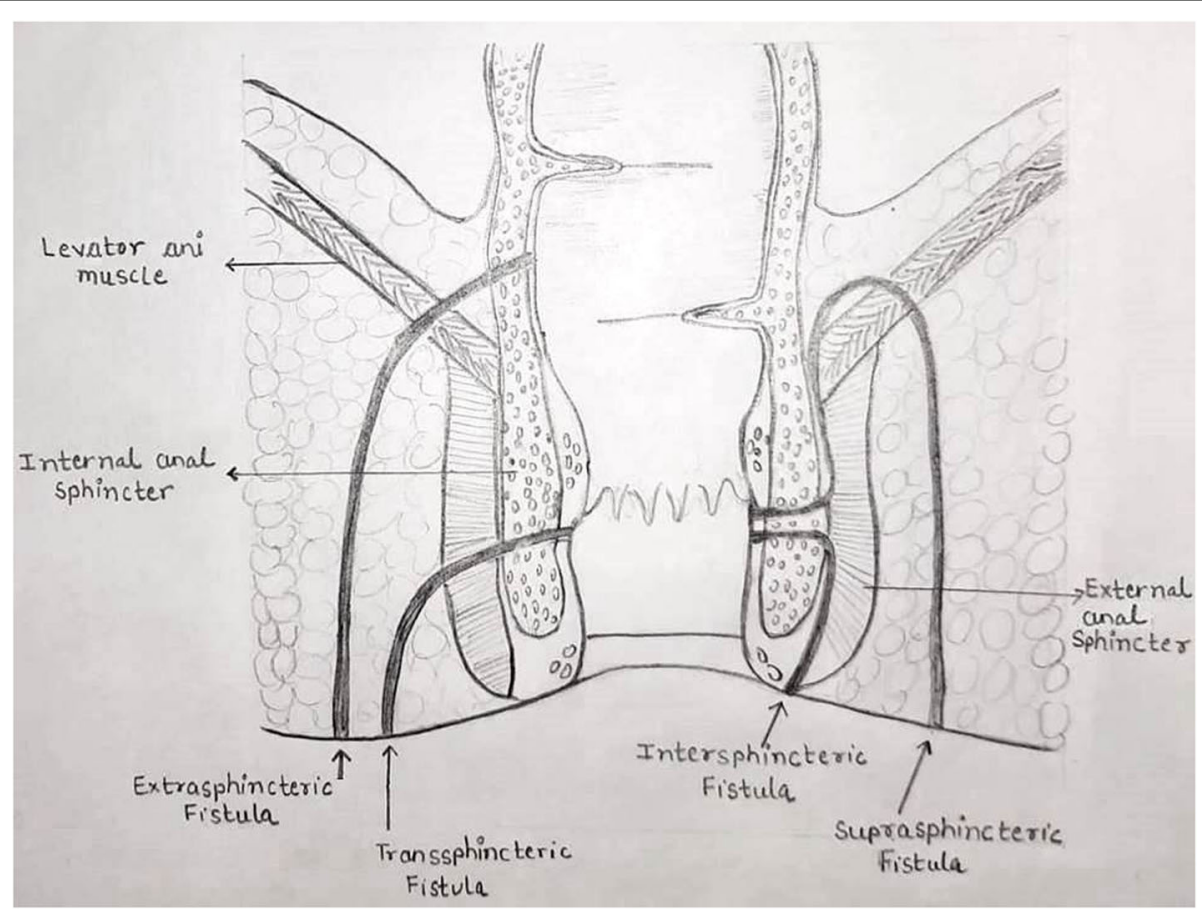

Fig. 1 Diagram showing four types of fistulas described by Parks 
surgery. X-ray fistulography, computed tomography scanning, endoanal or transrectal ultrasonography, and magnetic resonance imaging with fistulography are the radioimaging techniques which have been there for the last few decades to provide assistance to the surgeons in correct diagnosis of fistula in ano. In the forthcoming sections, an attempt has been made to review the role of different radio-imaging techniques in the diagnosis and evaluation of fistula in ano, particularly the complex fistula in ano.

\section{Main text}

\section{Plain X-rays}

Plain X-rays are the oldest radiological investigation used in clinical practice. Though not very useful in fistula imaging, plain X-rays of pelvic region may be helpful in the detection of gluteal or perianal abscesses by depicting the gas shadows in these areas (which is otherwise normally present in the rectum only) (Fig. 2). Moreover, the pathological conditions like tuberculosis and osteomyelitis of pelvic or spinal region may also be revealed in plain radiographs [9].

\section{X-ray fistulography}

$\mathrm{X}$-ray fistulography is a technique in which watersoluble radio-opaque contrast is injected into the fistulous track by cannulation of the external opening (or the internal opening in cases of blind fistulas) using a feeding tube, and radiographs are taken to visualize the fistulous track [3]. However, the technique gradually lost its diagnostic value due to a number of drawbacks. First, the contrast is usually injected slowly due to fear of tissue disruption or efflux of contrast through the external or internal opening which may cause the failure of secondary extensions to fill with contrast. Moreover, the extensions which are plugged with debris or are far from the primary track may also fail to fill with contrast making them difficult to be imaged. Second, as the anorectal musculature is not imaged, it becomes difficult to determine the course or location of track or abscess, if any, in relation to the anal sphincters or the levator ani. Third, the determination of the level of the internal opening is also often difficult due to a lack of precise landmarks. Efflux of contrast through the internal opening into the rectum also makes it difficult. Further, it may create a wrong impression of the presence of an extrasphincteric track. The fourth important drawback is that fistulography is an invasive technique and may result in dissemination of sepsis $[3,10]$. Cases have also been reported where the forceful injection of contrast has caused it to enter the pelvic veins which might lead to portal pyemia [9] (Fig. 3).

In 1974, Deshpande and colleagues from Banaras Hindu University develop a modified form of fistulography, called as Deshpande's technique of double-contrast X-ray fistulography wherein they used air filled in a condom balloon placed inside the rectum as the second contrasting agent along with metal markers at the anal verge and external opening (Fig. 4). The benefit of this technique lies in the fact that the fistula anatomy can be interpreted in relation to the anal canal, rectum, anorectal junction, and other anatomical landmarks which provide more information in comparison to conventional X-ray fistulography described above [8], but no definite published reports are available about Deshpande's technique.

\section{Computed tomography (CT) scanning}

Computed tomographic scanning is a specialized form of radiography in which multiple X-rays of the part to be evaluated are taken at different angles and projections,

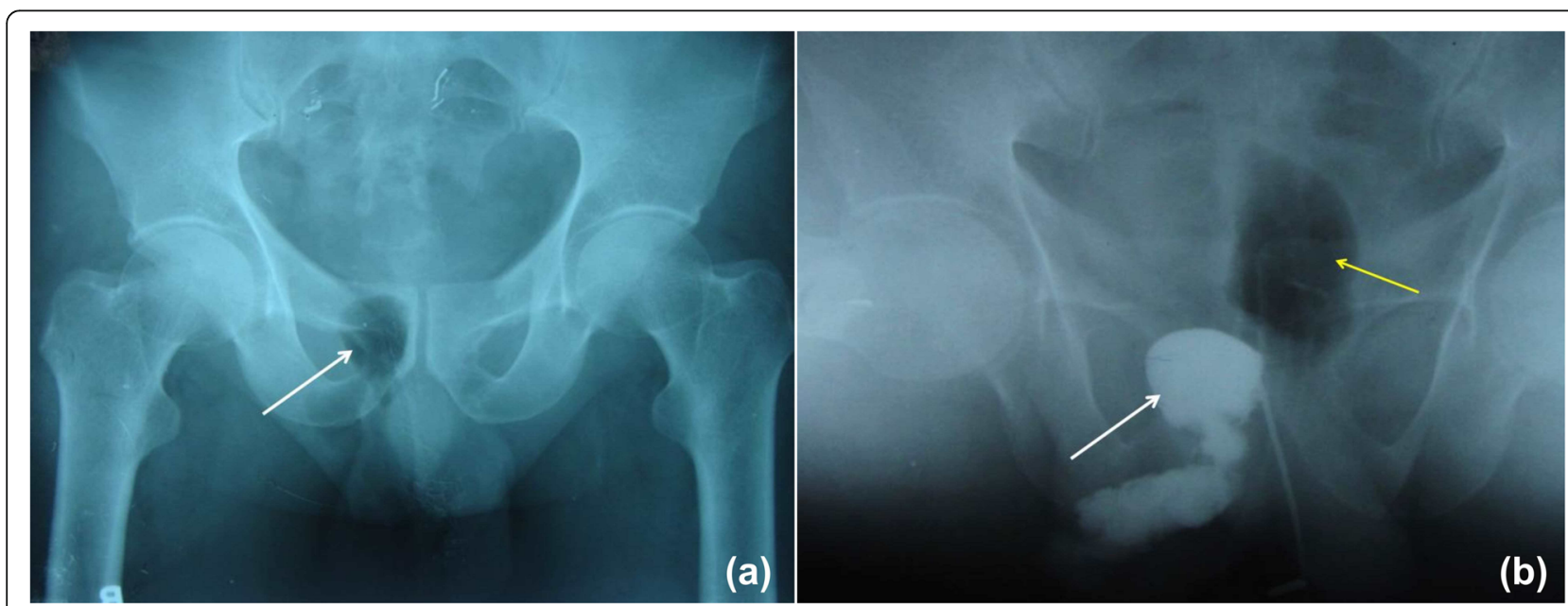

Fig. 2 a Plain X-ray pelvis (AP view) demonstrating gas shadow on the right perianal and gluteal region (white arrow). b X-ray fistulogram (Deshpande's technique) of the same patient showing abscess cavity filled with radio-opaque contrast extending towards right gluteal region (white arrow) with gas-filled in the rectum (yellow arrow) 


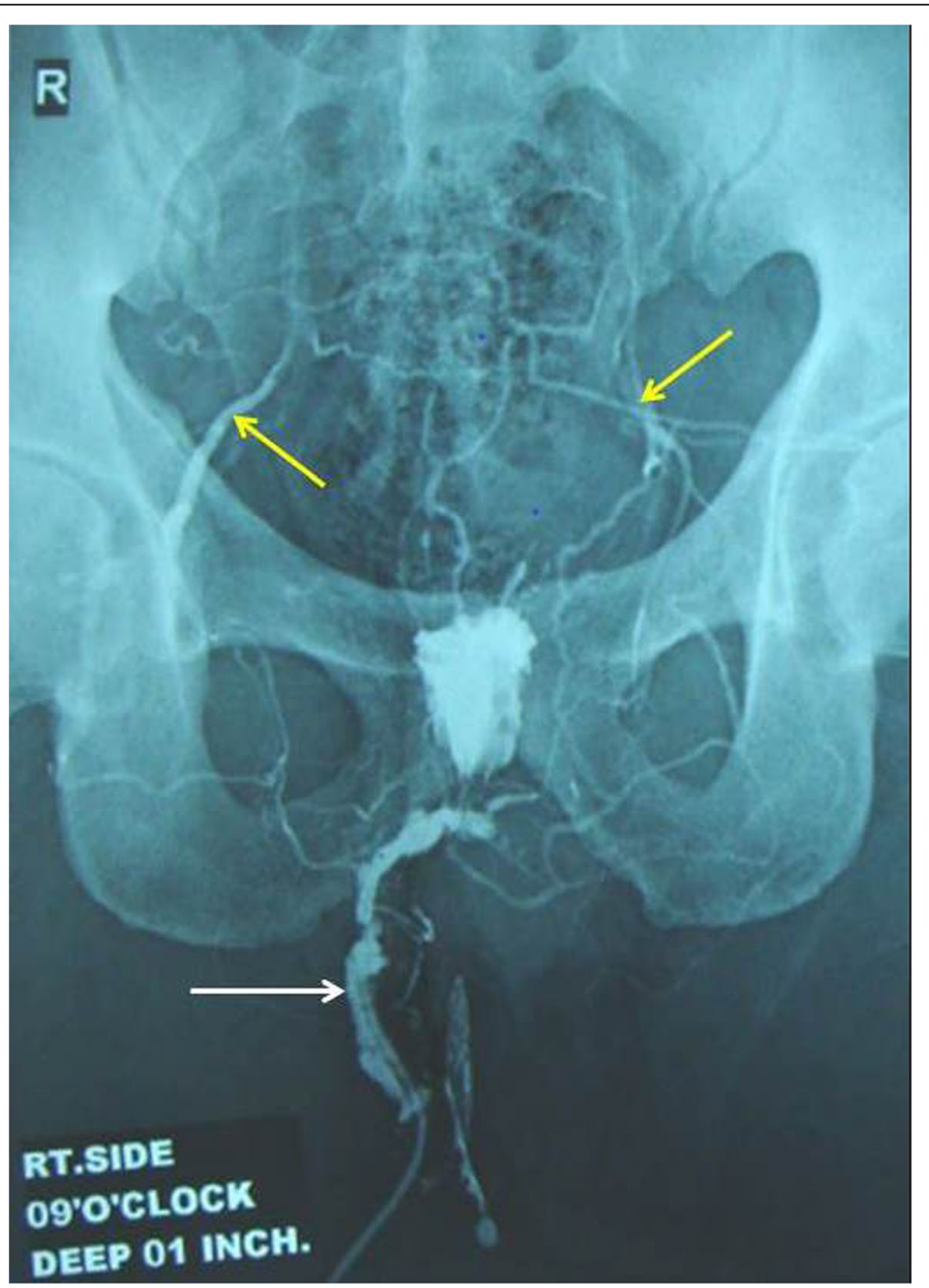

Fig. 3 X-ray pelvis with fistulogram (AP view) showing contrast material in the portal venous circulation (yellow arrows) due to forceful injection of contrast material into the fistulous track (white arrow)

and the information gathered is then reconstructed to produce a two-dimensional grayscale image of a slice through the body [11]. Though CT has a higher spatial and contrast resolution as compared to X-rays, it is not much useful in fistula imaging. It can identify the existence of fistulous tracks either through non-ionic water-soluble contrast inserted per rectum or through the external opening but it is still not sufficient for a detailed analysis of relative fistulous anatomy in order to classify it accurately. The reason behind is that the CT attenuation of the sphincter muscles and the pelvic floor musculature is similar to that of fistula itself, unless it has some air or contrast inside [12, 13]. Hence, CT fistulography with the use of contrast media may overcome some of the shortcomings of CT (Fig. 5). But, like X-ray fistulography, the secondary tracks or even the primary also may fail to fill with contrast if plugged with debris, thus adding more to the disadvantages of CT [14]. The visualization of tracks in relation to levator muscles is also not clear [3]. Compared with MRI, the differentiation between inactive fibrosed tracks and active disease is also poor by CT. However, CT scanning may be useful in inflammatory bowel disease to assess the extent of rectal inflammation and in the evaluation of acute inflammations or abscesses associated with fistula $[8,14]$. Overall, it can be said that CT is usually limited to the diagnosis of fistula-associated pelvic or other abscesses and in cases where MR evaluation is otherwise contraindicated [12].

\section{Endoanal or transrectal ultrasonography (EUS/TRUS)}

Anal endosonography, also known by names EUS or TRUS, was first described by Bartram and Law in 1989 and was the first technique to demonstrate the detailed anatomy of anal sphincter complex [15]. It has nowadays been widely accepted as a popular imaging modality for 


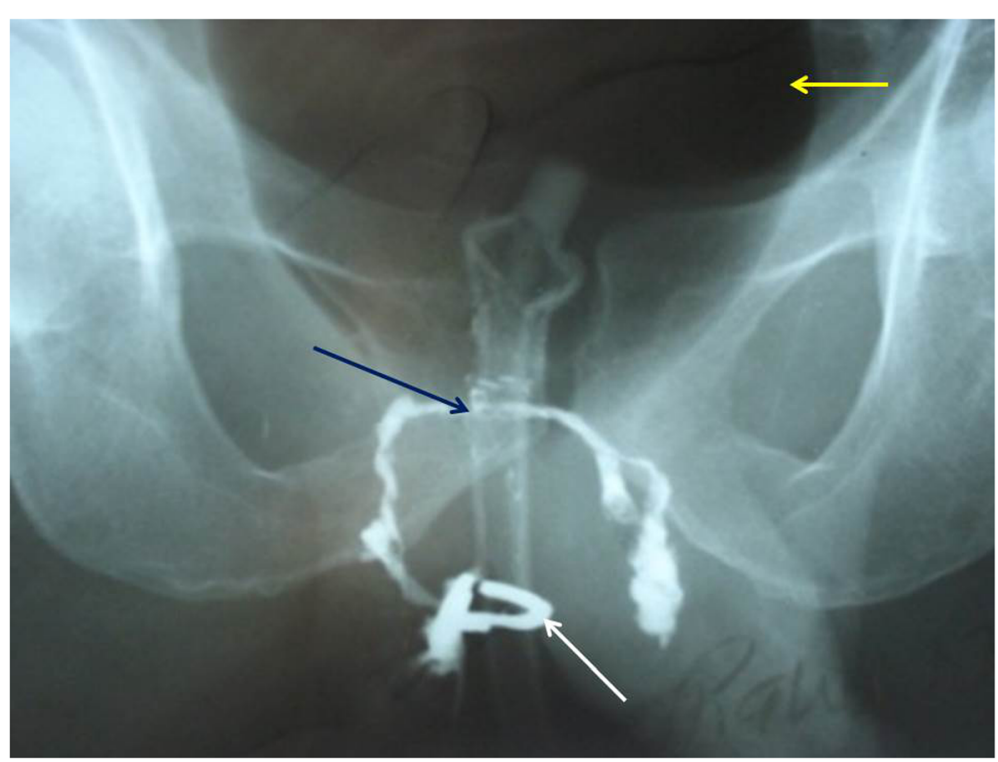

Fig. 4 X-ray fistulogram of a semi-horseshoe fistula showing Deshpande's technique of double-contrast fistulography with malecot rubber catheter in the anorectal canal to fill air into the rectum (yellow arrow) with a metal marker at anal verge (white arrow). Blue arrow demonstrates the level of the anorectal junction

evaluating the lower rectum, anal sphincters, and pelvic floor in patients with various anorectal diseases as it provides excellent visualization of the layers of the rectal wall and the anal anatomy [16]. Initially, EUS was not that much satisfactory as it was expected but the recent technological advancements in the form of threedimensional ultrasonography (3D EUS or 3D TRUS) and the use of $\mathrm{H}_{2} \mathrm{O}_{2}$ contrasts has improved its accuracy [17]. In modern 3D EUS, the examination is usually done by using a long, cylindrical transducer containing a $360^{\circ}$ rotating probe of frequency range $6-16 \mathrm{MHz}$ at its anterior end (imaging head) which is supplemented with a water-standoff system to give better images of the rectal and perirectal anatomy. The examination is usually performed in the left lateral position, knee-chest, or prone position [12, 16]; the authors however prefer to do the examination in a dorsal lithotomy position. The probe is gently introduced into the rectum through an anal orifice and gradually withdrawn through the anal canal till the lower end of the imaging head of the transducer lies at the anal verge and whole of the pelvic floor and sphincter complex is in vision.

On EUS examination, the anatomy of rectum and anal canal is visualized as areas or layers of hypo (grayish) or hyperechogenicity (whitish). The structure of the rectum is visible as five layers. The innermost hyperechoic line

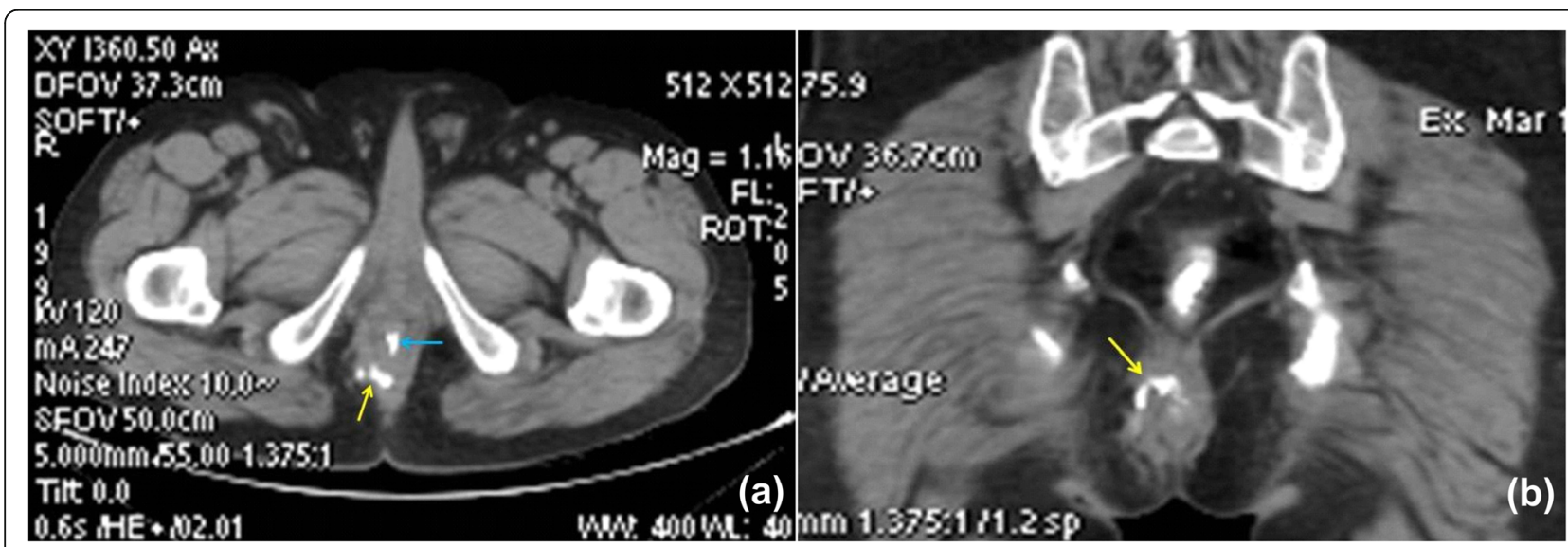

Fig. 5 CT fistulogram of a transsphincteric fistula in ano on the right perianal region with upper and lower arms and internal openings in both anterior and posterior midline. a Transverse image showing lower arm of the track entering into the anal canal posteriorly (yellow arrow) with contrast in the rectum (blue arrow). b Coronal image showing upper arm of the track entering into the anal canal anteriorly 
represents the interface of the balloon (which contains water) and the mucosal surface of the rectal wall followed by the inner hypoechoic layer representing the mucosa and muscularis mucosae and a slightly thicker hyperechoic submucosal layer, then the outer hypoechoic layer representing the muscularis propria followed by the outermost hyperechoic layer which represents the perirectal fatty tissue. The EUS anatomy of the anal canal is usually described at three levels: upper, middle, and lower anal canal. The middle anal canal is characterized by the presence of a hypoechoic ring encircling the anal canal like a band which represents the internal anal sphincter lying outside to the hyperechoic submucosa (Fig. 6). The external sphincter lies outside to this band of internal sphincter as a broad hyperechoic region [16], which some scholars have referred to as of mixed echogenicity [12]. The thickness and echogenicity of the internal sphincter increase with age $[18,19]$. In the lower anal canal, the hypoechoic band of the internal anal sphincter terminates and the hyperechoic subcutaneous external anal sphincter is present outside the submucosa. The upper anal canal is characterized by the presence of puborectalis muscle which appears as a U-shaped echogenic band (or a horse-shoe shaped sling) [16] (Fig. 7). The intersphincteric space and the longitudinal muscle lie in between the sphincters and are of mixed echogenicity [12].

Fistula tracks may appear of variable echogenicity on TRUS examination depending on the internal composition or stage of inflammation. While an active fistula track may contain fluid-like material, inactive tracks are usually tubular, fibrotic bands without fluid content. Usually, anal fistulas appear as hypoechoic tracks on TRUS examination while the abscesses may also contain hyperechoic debris or air bubbles [16]. TRUS is particularly well suited for the identification of internal opening as it is usually present at the probe surface. Ideally, the internal opening may be seen as a breach in the subepithelial layer of the anal canal (Fig. 8); however, it may not be so in all cases as the internal opening may be plugged with debris in some cases and the track

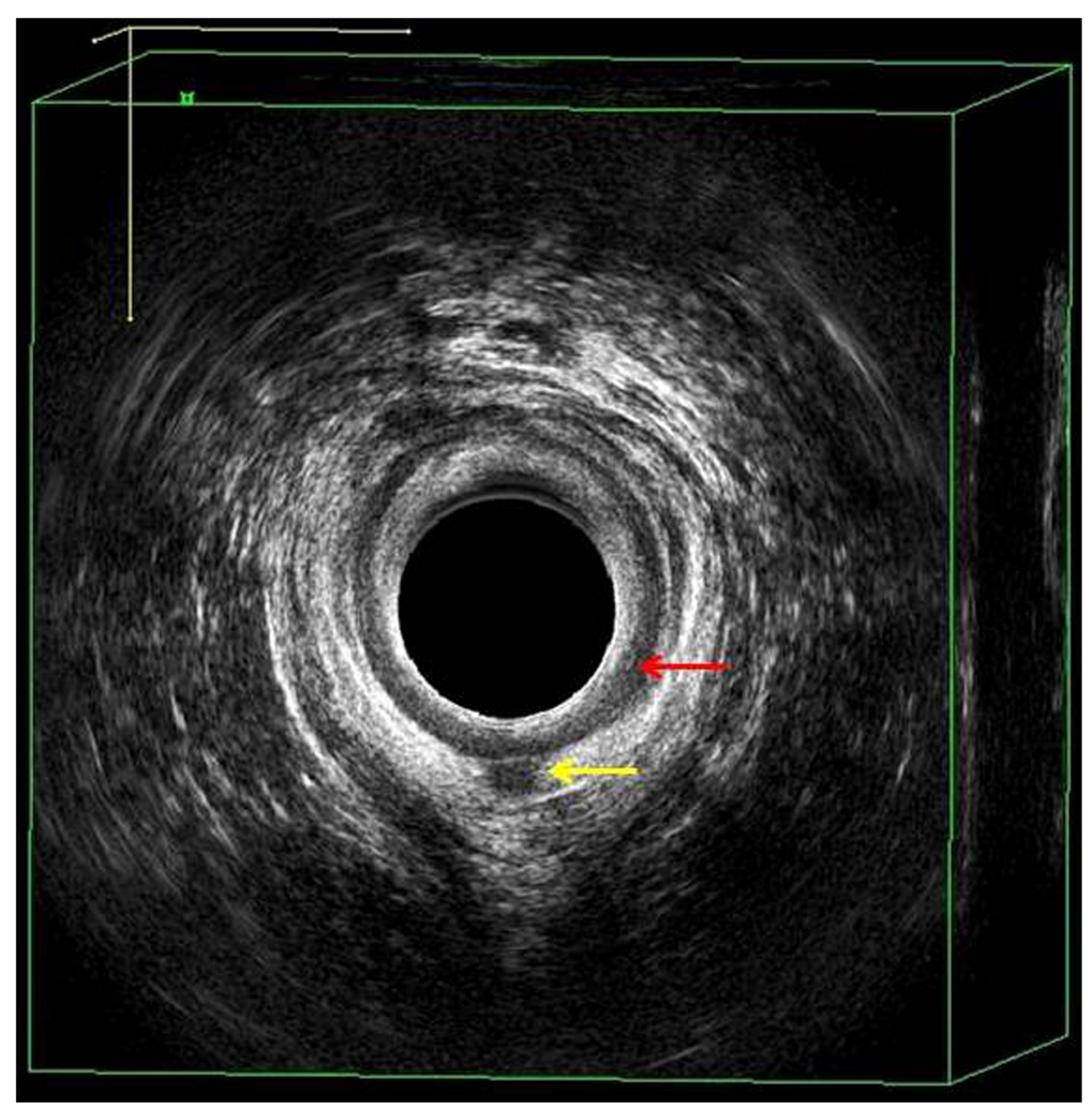

Fig. 6 3D TRUS image of intersphincteric fistula (hypoechoic area marked by the yellow arrow) at mid anal canal level. Red arrow demonstrates the hypoechoic internal sphincter ring (imaging performed with BK medical 3D Endoanal USG transducer Type 2052 with Flex focus scanner Type 1202) 


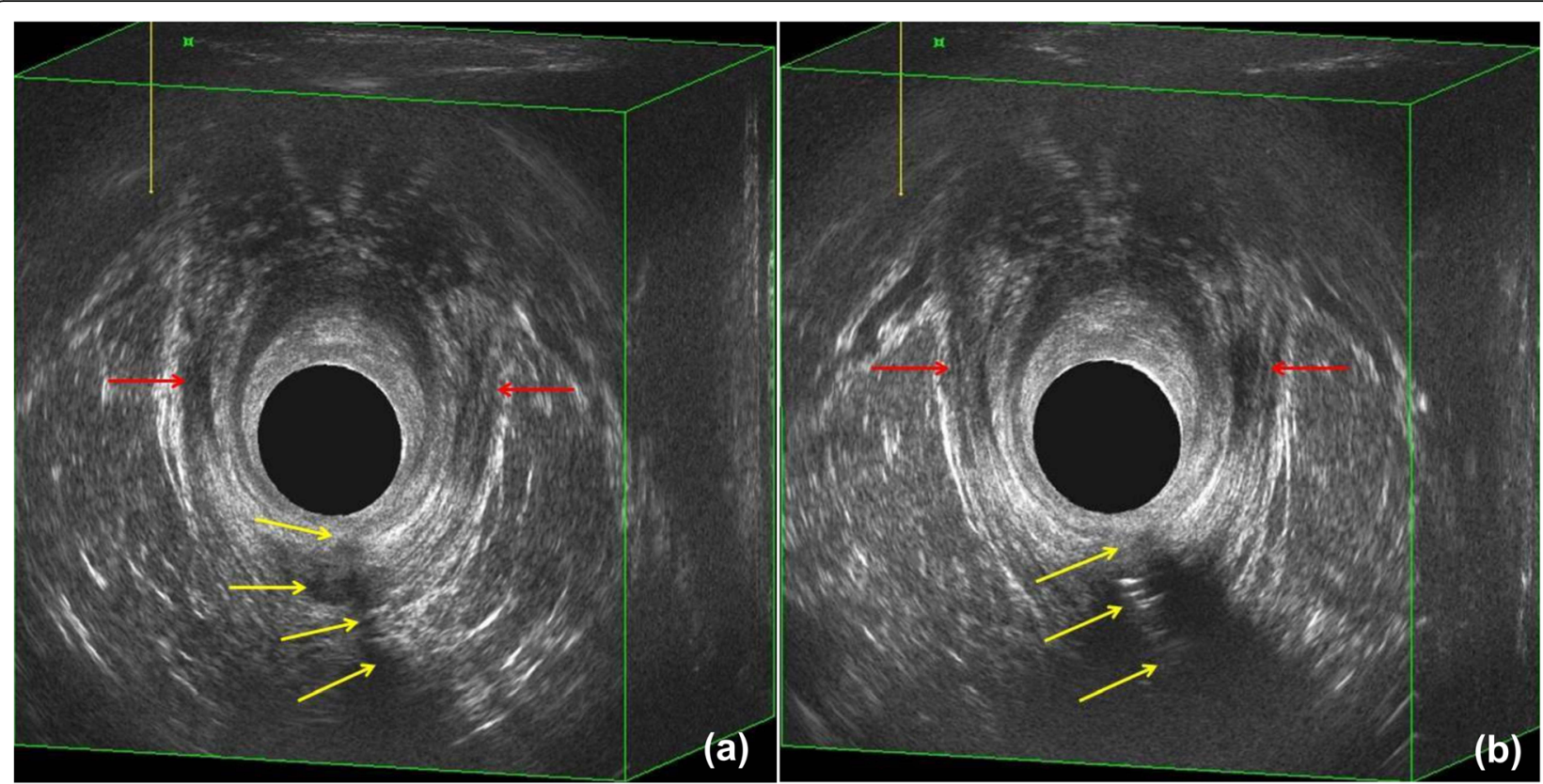

Fig. 7 3D TRUS image of a transsphincteric fistula (marked by yellow arrows) at the upper anal canal level. a Hypoechoic area before $\mathrm{H}_{2} \mathrm{O}_{2}$ instillation. b Hyperechoic shadow after $\mathrm{H}_{2} \mathrm{O}_{2}$ instillation. Red arrows demonstrate the puborectalis sling

extending up to the mucosal layer may not always be seen on endosonography. In those cases, the location of the internal opening may be revealed as a hypoechoic focus in the intersphincteric space with a small corresponding defect in the internal sphincter. The intersphincteric fistulas are very well visualized on TRUS as the hypoechoic collections limited to the intersphincteric region (Figs. 6 and 9) while the transsphincteric tracks are seen as hypoechoic fluid collections extending through the external sphincter region into the ischiorectal fossae [12] (Figs. 7, 8, 10, 11, and 12). The 3D endosonography gives an excellent view of the fistula tracks with image reconstructions in all relevant planes like axial, coronal, sagittal, and oblique. This has made it easier to differentiate between low transsphincteric, high transsphincteric, or suprasphincteric tracks by depicting the level at which the track crosses the external sphincter [17]. While the extrasphincteric hypoechoic tracks are found to be lying outside the external sphincter, the intersphincteric fistulas lie medial to external sphincter as hypoechoic cords or collections contained within the intersphincteric space when viewed in coronal or sagittal images depending upon the location of the track.

Despite all these merits, TRUS has got some specific disadvantages also which may affect its accuracy and results in the diagnosis of fistula in ano. First is that it is highly operator dependent, and so, the artifacts may also be mistaken as tracks by some and not by others. Next is its limited field of view beyond the region of the external sphincter, particularly at high frequencies, which makes it difficult to follow the whole course transsphincteric or suprasphincteric fistulas. Another important disadvantage is its inability to differentiate between the areas of fibrosis and infection, which is particularly important in cases of recurrent fistulas, as both appear hyperechoic on endosonography. The use of $\mathrm{H}_{2} \mathrm{O}_{2}$ contrast injections to demonstrate the patent tracks has its advantages in such cases, but again, it may fail to fill an active track which is otherwise plugged with debris. Moreover, the gas formed within the tracks due to the use of $\mathrm{H}_{2} \mathrm{O}_{2}$ may cause acoustic shadows which may be mistaken as extensions $[12,16]$.

\section{Magnetic resonance imaging (MRI)}

MRI is an imaging modality that uses non-ionizing magnetic radiation to create useful diagnostic images. Though the first use of MR imaging in the evaluation of fistula was done by Koelbel et al. in 1989 in cases of Crohn's diseases [20], the first dedicated study demonstrating the potential of MR imaging in the evaluation of fistula in ano was published in 1992 where Lunniss et al. showed an accuracy of $88 \%$ (14 out of 16) when compared to surgical exploration [21]. During subsequent years, MR imaging evolved as the imaging modality of choice for fistula in ano due to its superior contrast resolution and ability to display the perineum and pelvic anatomy in orthogonal axes, thus allowing good demonstration of anatomy and pathology of the tracks [22]. MR imaging has seen a lot of technical advances since its inception, whether it is in the strength of magnetic 


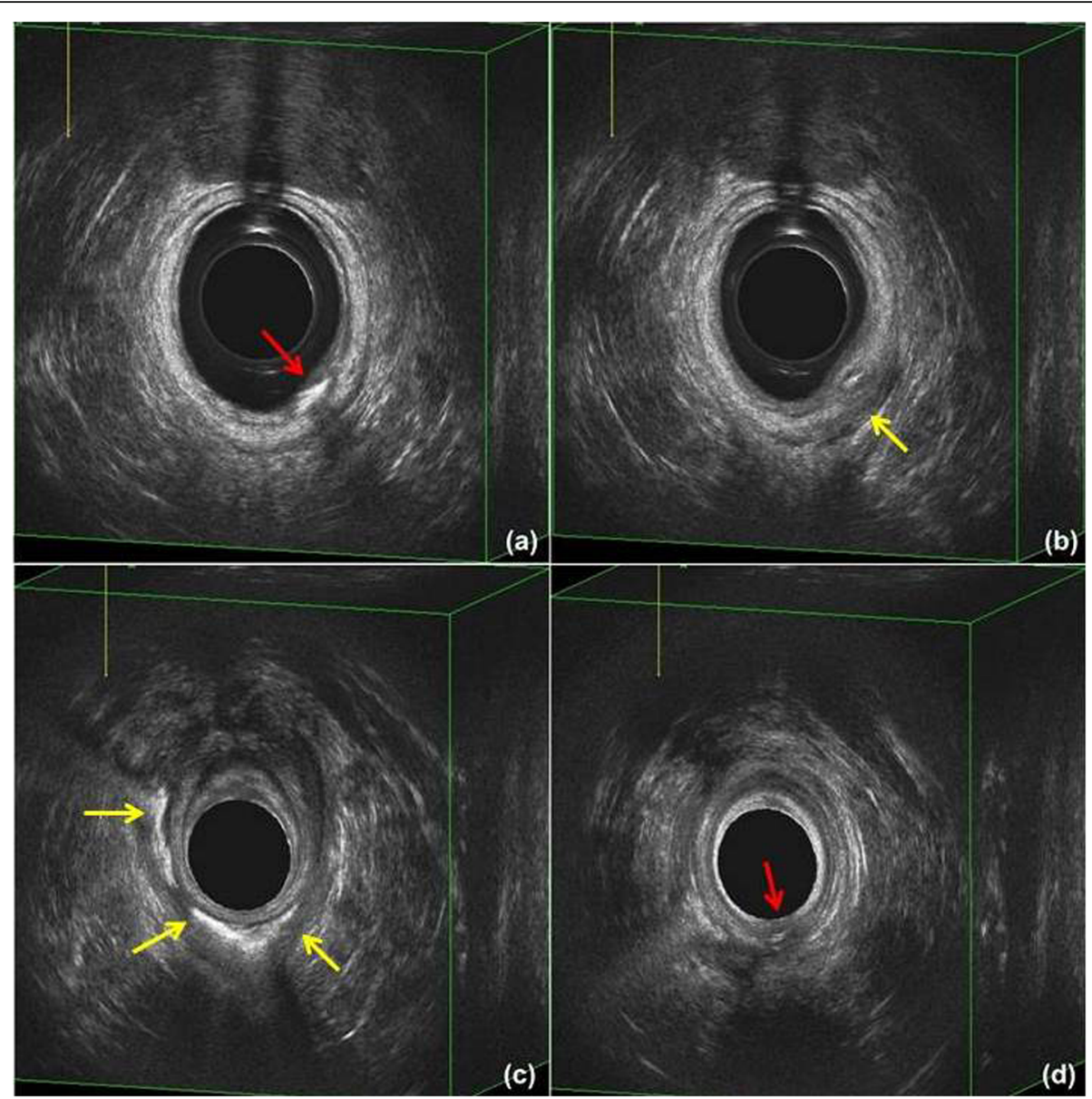

Fig. $8 \mathrm{H}_{2} \mathrm{O}_{2}$-enhanced 3D TRUS images of transsphincteric fistula with bilateral intersphincteric extension with two internal openings. a Red arrow demonstrates the secondary internal opening as a breach in the continuity of the epithelial layer of the rectum at the posterolateral wall $\mathbf{b}$ and $\mathbf{c}$. The course of track shown as a hyperechoic shadow $\mathbf{d}$. The red arrow demonstrates the primary internal opening inside the anal canal as a breach in the continuity of the epithelial layer at mid anal canal level

field (1 Tesla, 1.5 Tesla, 3 Tesla) or in the field of MR coils (body coil, surface coils, or the most recently employed endoluminal coils) or MR sequences (spinecho sequences, inversion sequences, contrast-enhanced sequences, etc.). The choice of all these preferably depends upon availability, in addition to personal preferences, patient group studied, or the clinical question in demand [12]. Various studies have demonstrated the advantages or disadvantages of one technique over the other. Though T1-weighted (T1W), T2-weighted (T2W), fat suppression, and contrast-enhanced images usually constitute a general spectrum of image sequences for fistula in ano, the use of diffusion-weighted (DW) imaging and subtraction MR fistulography have also been recommended recently to aid in diagnosis [23, 24]. The images are usually taken in oblique transverse and coronal planes aligned orthogonal and parallel to anal sphincters respectively, in the mid-sagittal line.
In general, fluid, muscles, and fat have low, intermediate, and high signal intensity, respectively, on low TR/ TE (T1W) images, while on high TR/TE (T2W) images, the fluid appears hyperintense with the other structures showing same intensity pattern [25]. The sphincters, the conjoint longitudinal muscle, and the levator ani complex show medium level soft tissue intensity pattern against the contrast provided by the interposed fat, and the fat and fascia in the adjacent ischioanal and ischiorectal fossae. However, the internal sphincter (being composed of smooth muscles) appears relatively hyperintense than the external sphincters and puborectalis (which are composed of striated muscle fibers) on all sequences [26]. On fat-suppressed sequences, the soft-tissue contrast between all these structures is significantly reduced offering an advantage towards the visualization of pathology at the cost of normal anatomical structures (Fig. 13) [12, 19, 27-30]. 


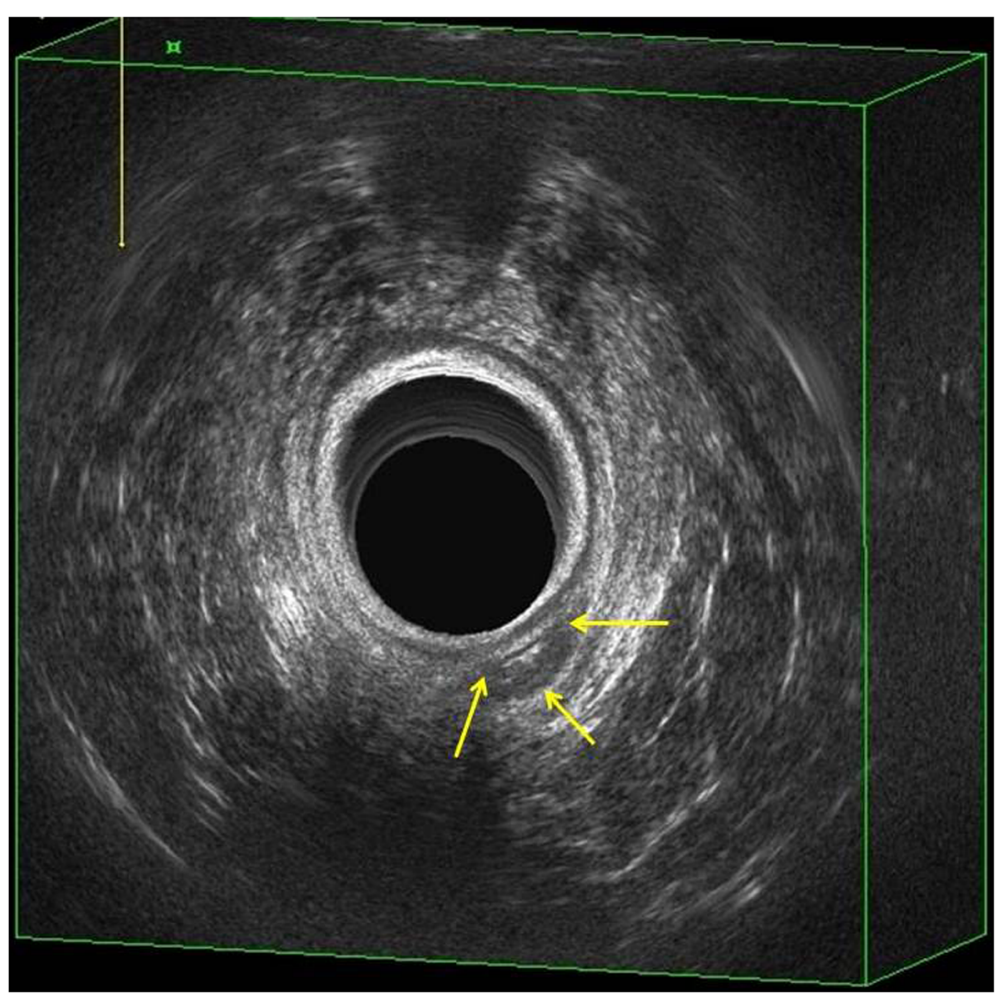

Fig. 9 3D TRUS image of a blind intersphincteric fistula (hypoechoic area marked by yellow arrows) at the upper anal canal level

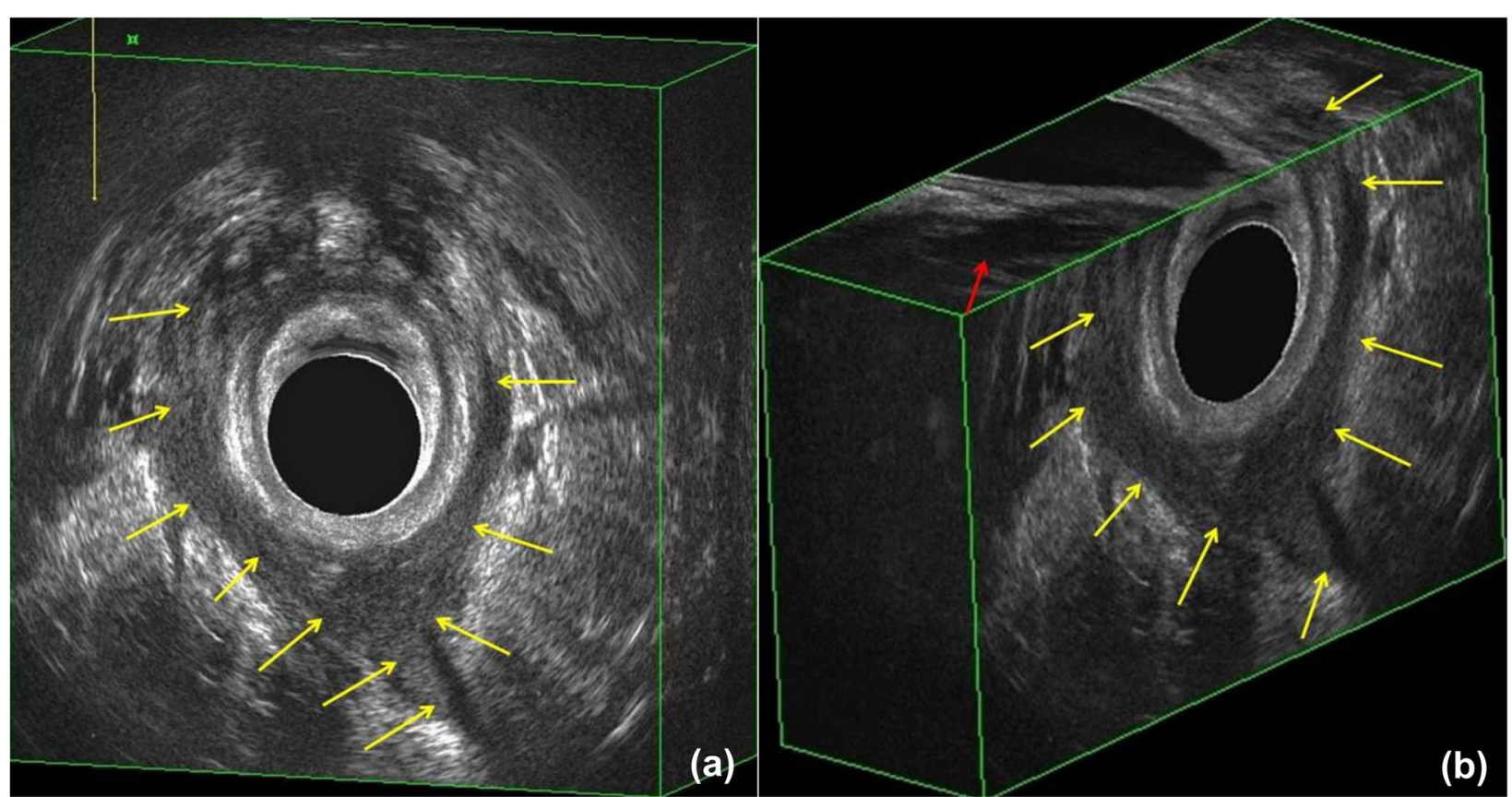

Fig. 10 3D TRUS image of transsphincteric fistula with secondary extensions into bilateral intersphincteric plane (hypoechoic area marked by yellow arrows) at the upper anal canal level. a Axial view. b Section showing the involvement of the right levator plate with edema (red arrow) 


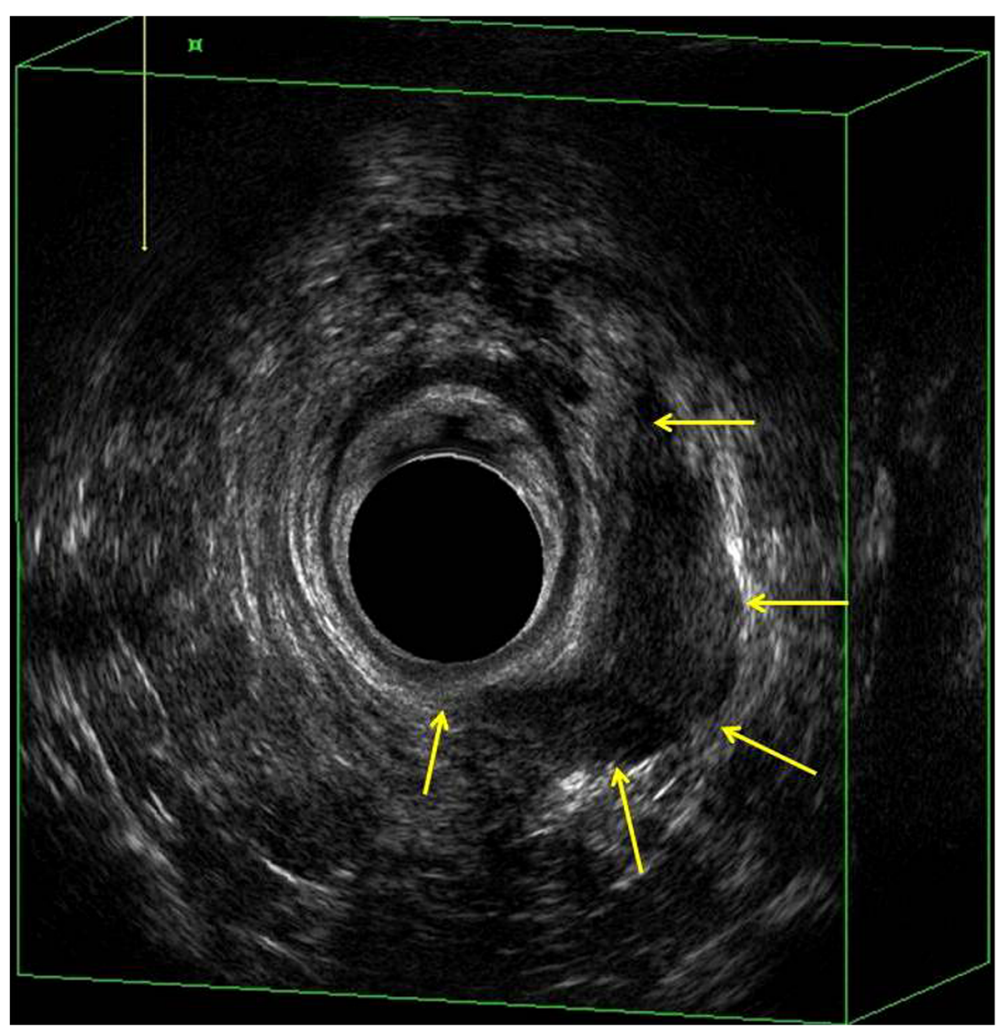

Fig. 11 3D TRUS image of transsphincteric fistula with left ischiorectal abscess (hypoechoic area marked by yellow arrows) at the level of junction of the mid- and upper anal canal

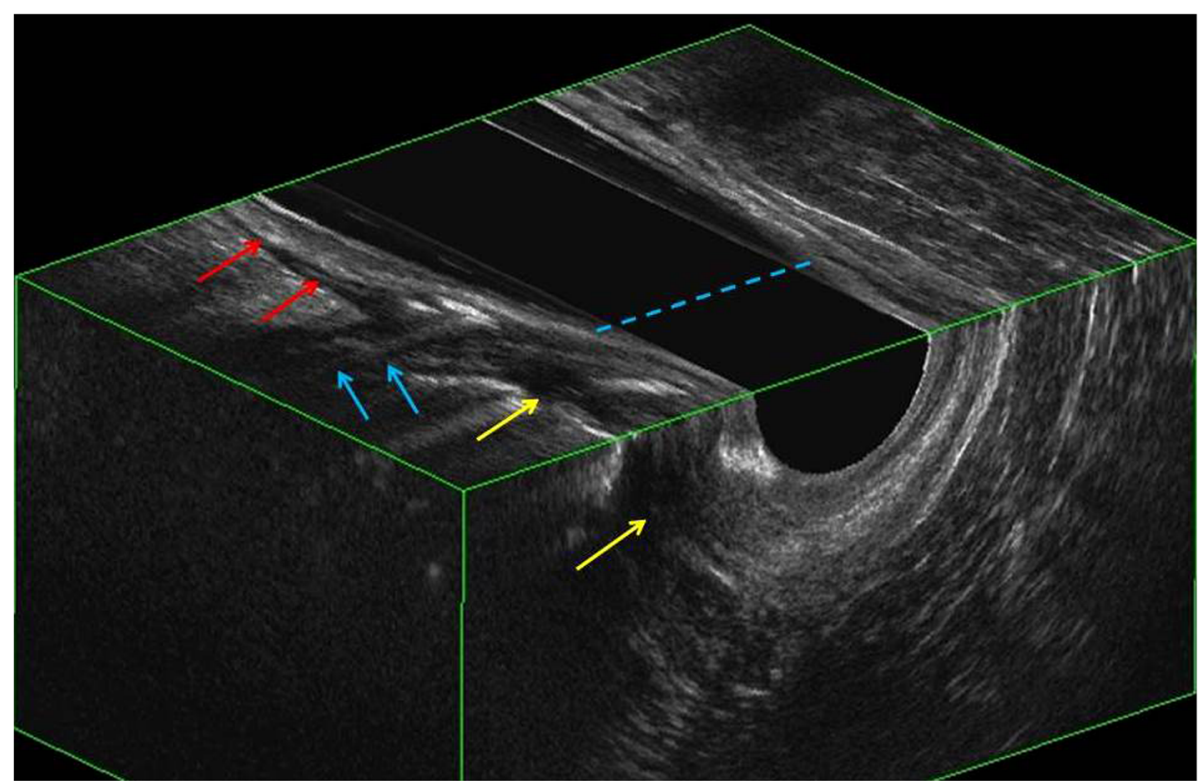

Fig. 12 Section of 3D TRUS image of transsphincteric fistula (yellow arrows) with supralevator extension (red arrows) through the right intersphincteric plane. Blue dotted line marks the level of the anorectal junction and the blue arrows mark the levator plate 

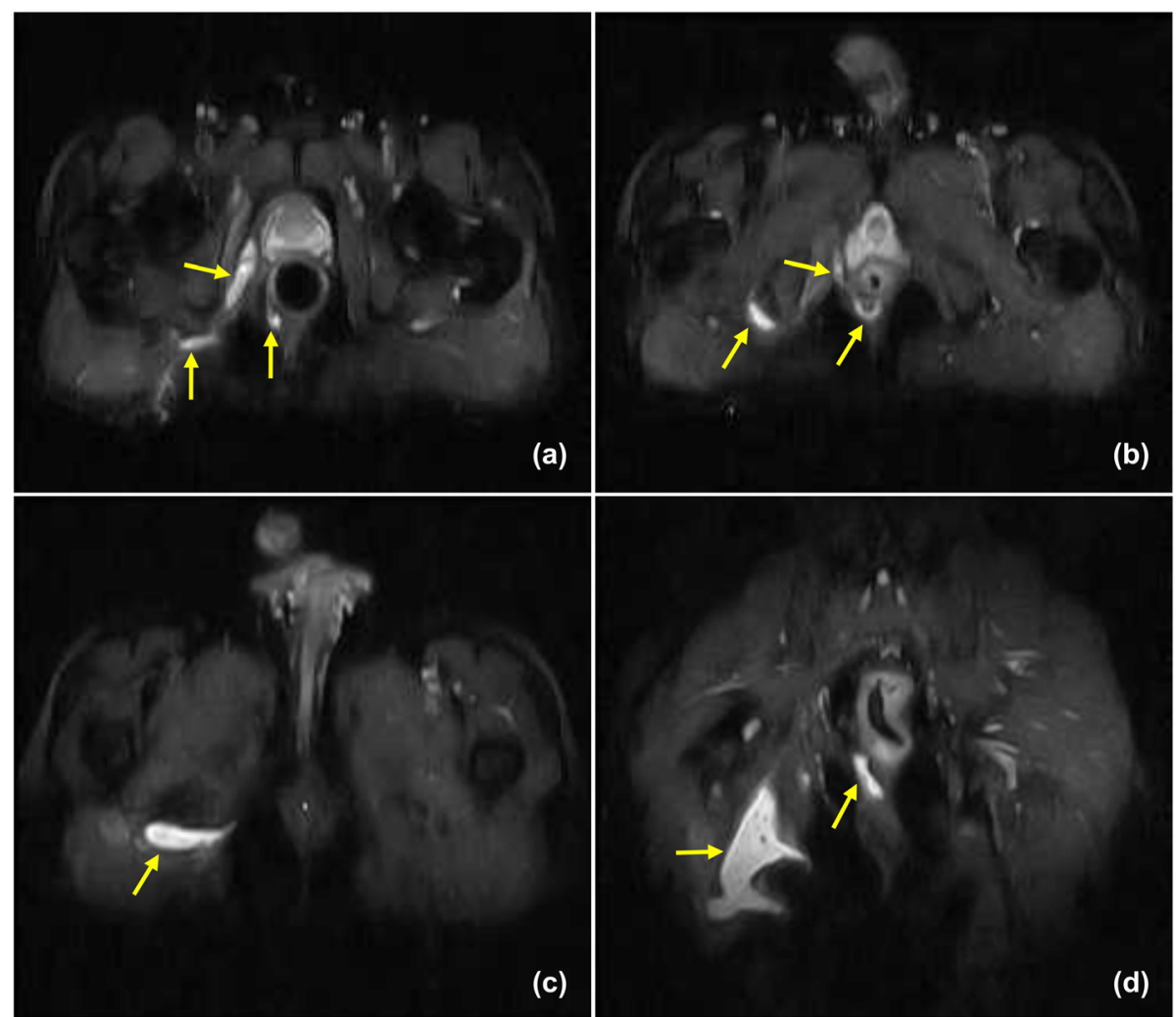

Fig. 13 MR Pelvis FS T2W. a-c Axial and $\mathbf{d}$ coronal image of a complex fistula showing transsphincteric track with gluteal abscess (yellow arrows)

The MR imaging features of the fistulous track depend upon their activity status and chronicity and varies on different sequences. The fat in ischioanal and ischiorectal fossae appears hyperintense on all sequences and enables accurate visualization of the surrounding anatomical structures like the sphincter muscles and levator ani. The visualization of fistulous track or abscesses however may remain ambiguous on low TR/TE sequences due to the signal intensity matching that of the anatomical structures and mandate sequences with either high or balanced TR/ TE values. On high TR/TE sequences, the active fistulous tracks having inflammatory fluid, pus or granulation tissue, and associated abscesses may have a hyperintense signal against the sphincters and levator plate (Fig. 14a, b). As the track becomes chronic, the increasing fibrosis in the wall of the track causes a progressive reduction in the signal intensity on all sequences. The thickness of this fibrous layer is proportional to the duration of disease and is more in the recurrent fistula. On the other hand, perilesional inflammation in an active (even if chronic) track (viz. surrounding the track) makes the whole complex appear brighter on high TR/TE images due to the presence of vasogenic edema and cellular infiltrates. Fat-suppressed sequences are obtained both with T2 weighting and with T1 weighting after administration of intravenous gadolinium, latter usually being a three-dimensional acquisition.
In these sequences, the tracks appear hyperintense against the hypointense fat (being suppressed) and iso-intense muscles (sphincters and levator ani) (Figs. 15 and 16). The fibrous wall of the track and granulation tissue described above shows enhancement on contrast-enhanced images, while the fluid (or pus) within the track does not enhance, thus making a differentiation between an active and a healing track possible. Similarly, the abscesses display low intensity in the center (due to pus) with peripheral ring enhancement [12, 30-32]. Chronic fibrotic tracks with the increased degree of fibrosis and the scar tissue appear hypointense on both T1W and T2W images but show delayed enhancement with intravenous gadolinium [31].

Based on the contrast-enhancement of inflamed fibrous walls of the track, Schaefer et al. proposed a new MRI protocol including 3D contrast-enhanced, highresolution fast low-angle shot (FLASH) sequence in the axial plane, and digital image subtraction. Fat-saturated T1W gradient-echo sequences were obtained in the axial plane before and after intravenous administration of contrast agent, and fat subtraction of unenhanced from contrast-enhanced sequences was performed. Because of the 3D data set, multiplanar reconstructions could be performed, thus generating an image similar to fistulography. The protocol was therefore termed as subtraction MR fistulography [24]. Further studies on this 

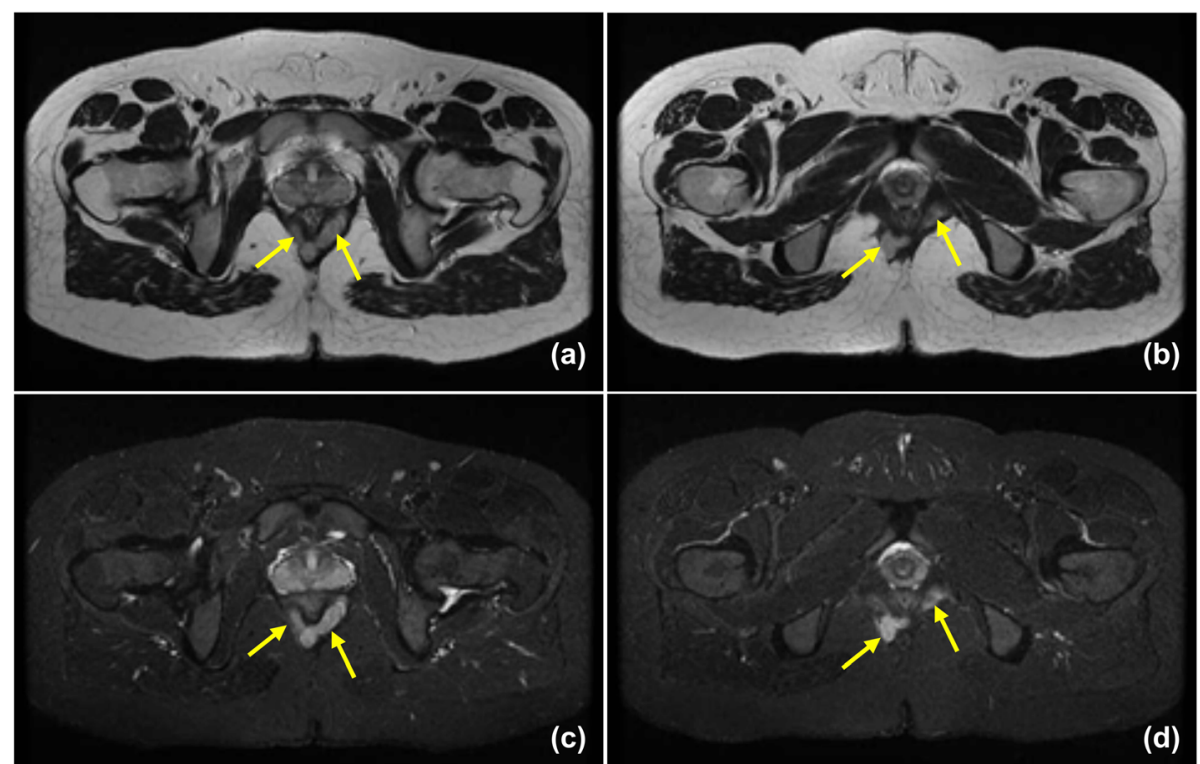

(e)

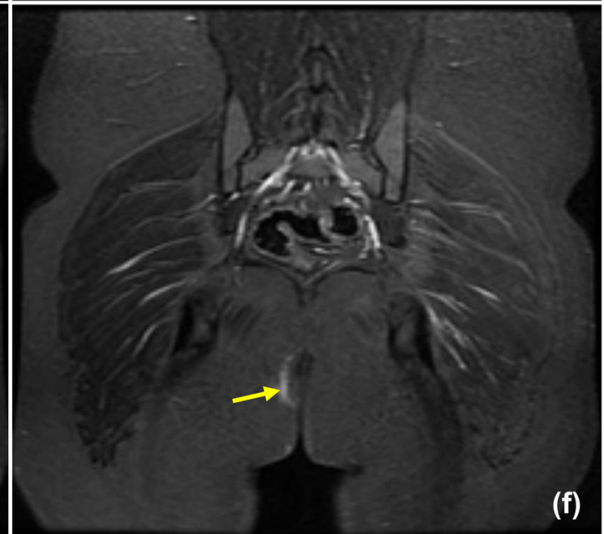

Fig. $14 \mathrm{MR}$ pelvis images of a transsphincteric fistula with bilateral intersphincteric extension. $\mathbf{a}, \mathbf{b}$ T2W axial, $\mathbf{c}$, d FS T2W axial, and e, f FS T2W coronal images showing the course of track and extension (yellow arrows)

protocol revealed significant differences in signal intensities between fistula and adjacent anatomical structures (sphincter, etc.), thus allowing better identification of presence, location, and extent of fistulas [33, 34].

Contrast-enhanced imaging has therefore become an important protocol in the diagnosis of fistula-in-ano as it helps in differentiating the disease activity and adds to the diagnostic value. However, an increase in cost and, more importantly, the contraindication for the use in cases with impaired renal functions have prompted to avoid the use of intravenous contrast [23]. DW imaging has therefore been proposed as an important alternative, owing to the fact that inflammatory lesions can be seen as high signal areas on DW imaging. The fistulous tracks appear hyperintense while the background signal is significantly suppressed on DW images; thus, the presence and extent of fistula can be detected clearly [23, 35]. Studies have concluded that the conspicuity of fistulous tracks is better on
DW-MRI than T2W images, thus increasing the sensitivity for its detection [23, 35, 36]. Moreover, DW-MRI has also been shown useful in depicting the disease activity in the fistula and in differentiating between an associated abscess and inflammatory mass using apparent diffusion coefficient (ADC) values [36, 37]. However, poor spatial resolution in DW images limits its ability to evaluate the course of fistulous track in relation to adjacent structures. Therefore, it has been recommended to be a part of the investigation protocol as an adjunct to $\mathrm{T} 2 \mathrm{~W}$ images in cases where the use of contrast is either avoided or contraindicated $[23,35,36]$.

In addition to these, another technical advancement in the form of three-dimensional (3D) T2W sequences has also been proposed recently to further improve the diagnostic efficiency [31]. Using 3D-T2W sequences, a single 3D sequence can provide data for post-processing reformation of images into any desired plane (axial, coronal, 

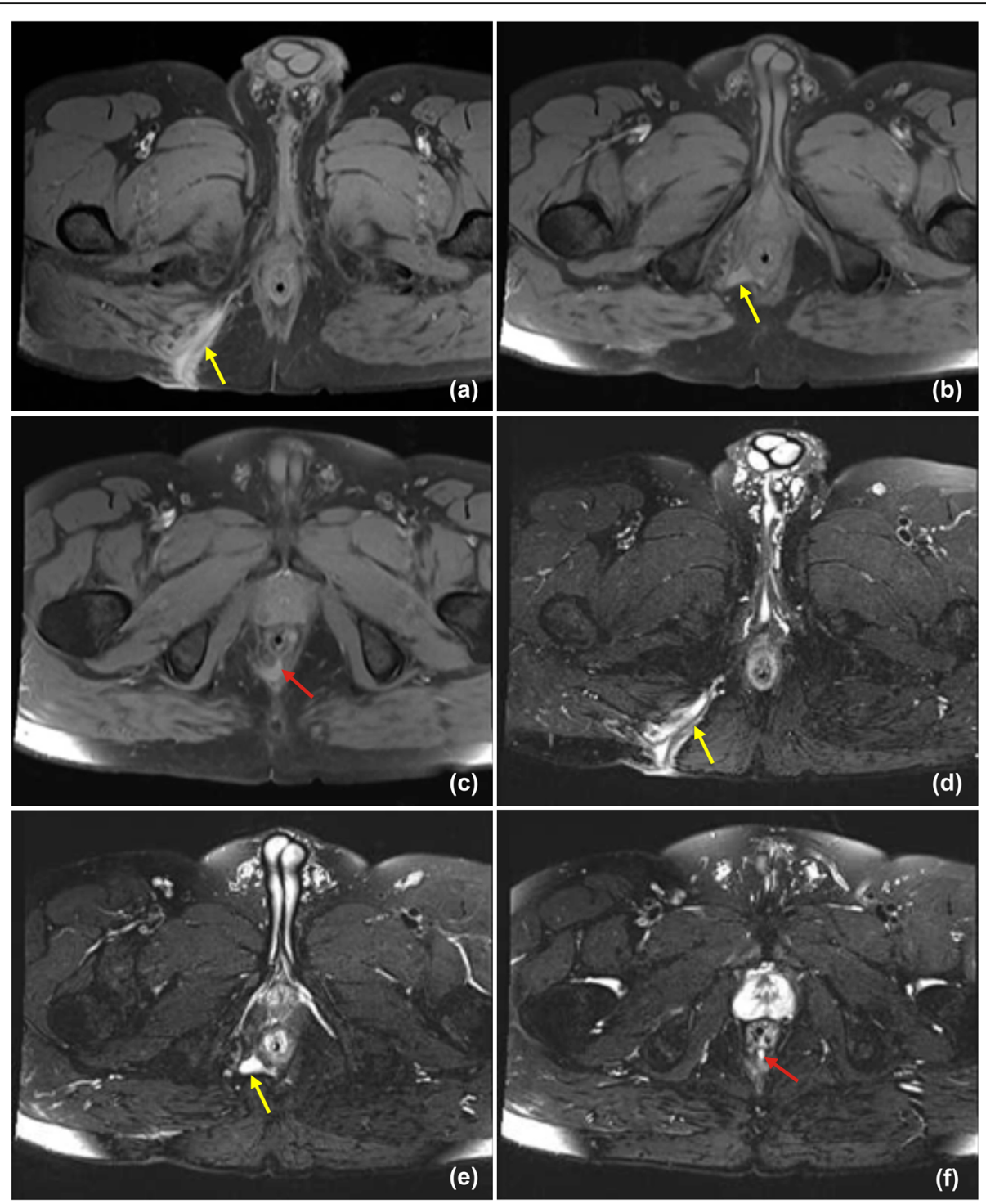

Fig. 15 MR pelvis images of a transsphincteric fistula. a-c FS T1W axial. d-f FS T2W axial images showing the course of track (yellow arrows) and the level of internal opening (red arrows)

and sagittal), thus reducing the imaging time. Other advantages include no operator dependency in acquiring images in obliquity, the ability to cover large volumes and acquisition of thinner sections without intersection gaps. In comparison to two-dimensional sequences, the quality of the image and the lesion-detection abilities are also not compromised [31,38].

For the classification of fistula, its relation with respect to the sphincter complex as well as the depiction of the location of internal opening is necessary. The extent of the primary track, whether limited within the intersphincteric space (intersphincteric fistula) or crossing the external sphincter is usually appreciated in transverse images while the infralevator or supralevator course of track, is usually seen in the coronal images as the levator plate is best depicted in the coronal plane [12]. Sagittal images are suitable for the demonstration of rectovaginal fistulae and the pre-sacral region [13]. Track visualized in the ischiorectal fossa may be transsphincteric, suprasphincteric, or extrasphincteric fistula. Transsphincteric fistulas crossing the external sphincters can be easily demonstrated on transverse or coronal images (Fig. 17). The fistulous tracks penetrating the pelvic floor above the level of puborectalis may either be suprasphincteric or extrasphincteric; the differentiation being made by the level of the internal opening being rectal in extrasphincteric and anal in suprasphincteric cases. Both these are appreciated well on coronal images as the pelvic floor, and the level of internal opening is best appreciated on coronal images. The radial site of 

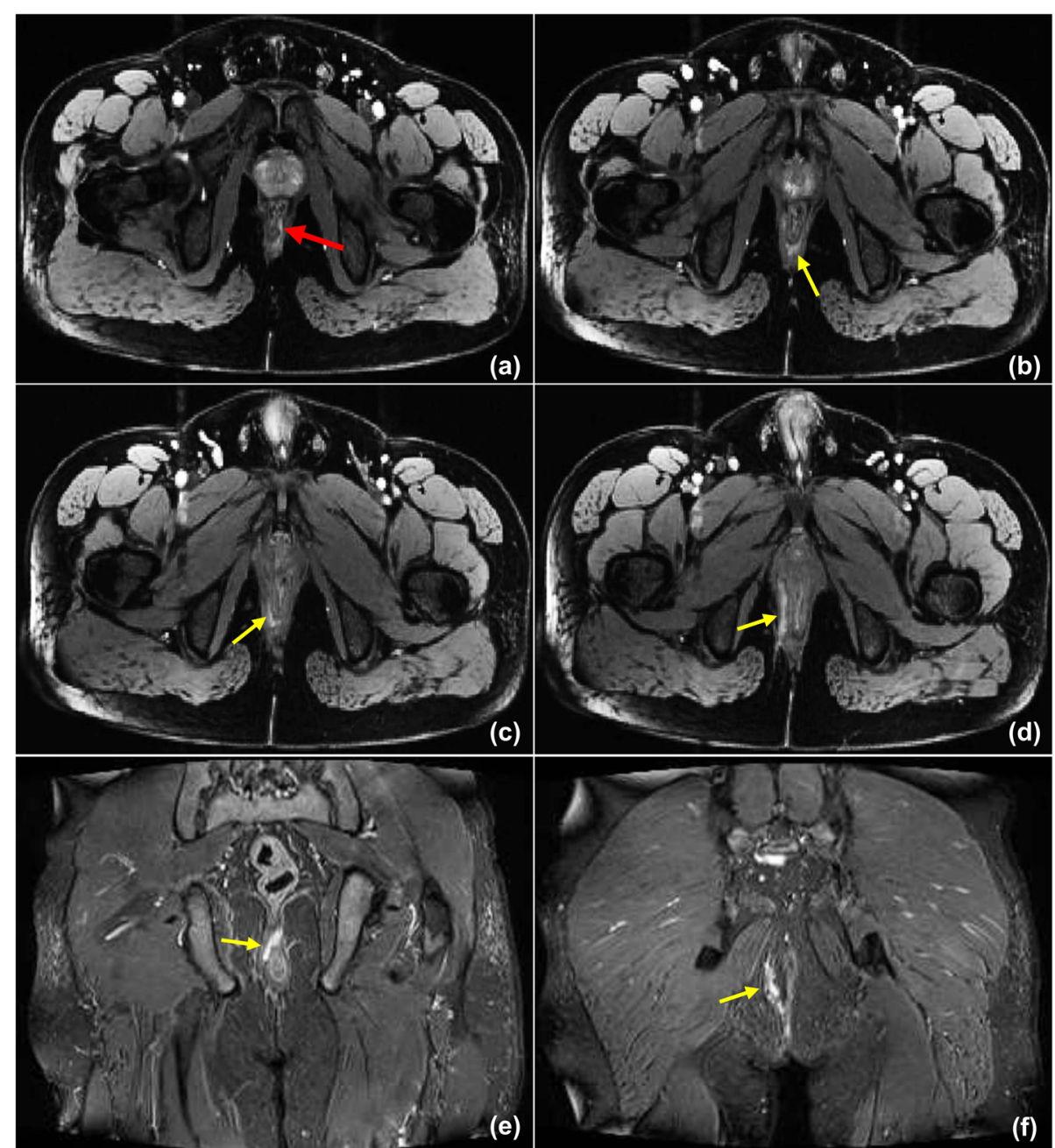

Fig. 16 MR pelvis images of the case depicted in Fig. 8. a-d FS T1W DE3D axial images. e-f FS T2W coronal images (TR/TE:5050/36). The red arrow demonstrates the level of internal opening in the lateral wall of the rectum while the yellow arrows demonstrate the course of track as high signal intensity

the internal opening is however usually demonstrated in the transverse plane. It is often difficult to define the exact location of internal opening as the track is usually not traceable up to the mucosa. The site is therefore predicted according to the area of maximal intersphincteric sepsis as the likelihood of internal opening being close to this area is usually more [12]. Apart from accurately defining the course of the primary track and the level of internal opening, MRI offers an important advantage of demonstrating secondary extensions which, if missed, may cause the disease to recur. The extensions display hyperintensity on T2W and STIR images and will enhance after the use of intravenous contrast. These may be present on ipsilateral or contralateral sides or may present as horseshoe extensions in intersphincteric, ischiorectal, or supralevator spaces [12, 39]. Based on MRI features, an MR imaging classification of fistula in ano is proposed by St. James University Hospital classifying the fistula in ano into grades 1 to 5 [Table 1].

\section{Discussion}

Recurrence is a common problem with fistula management, specially in recurrent and complex fistulas, which is usually due to missed or undetected infection at the time of surgery [12]. Over the years, preoperative imaging of fistula in ano has become a routine practice to help the surgeons understand the fistula anatomy and planning the appropriate management accordingly so that the chances of recurrence may be reduced. Plain Xrays are rarely used in anal fistula imaging nowadays and so is the case with $\mathrm{X}$-ray fistulography. The accuracy of $\mathrm{X}$-ray fistulography in identifying the internal opening and extensions has been found to be as low as $16 \%$ with false-positive rate of $10 \%$ [40] and hence is not considered reliable in correctly diagnosing fistula in ano. However, in certain cases like in extrasphincteric fistulas or in fistulas resulting due to inflammatory bowel disease, fistulography has been useful in demonstrating the 


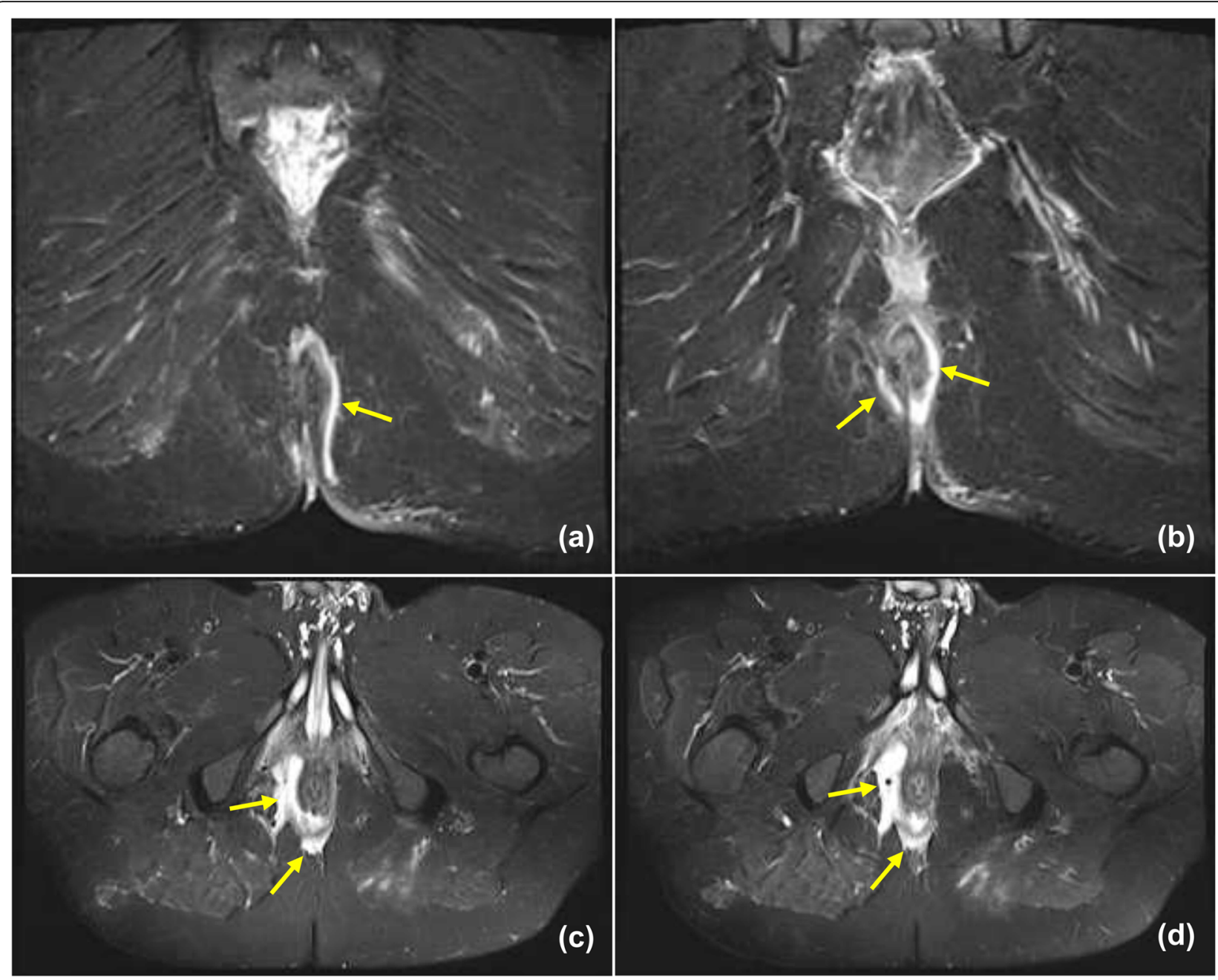

Fig. 17 MR Pelvis FS T2W. a, b Coronal images and c, d axial images of a complex transsphincteric fistula with intersphincteric horseshoe extension (marked by yellow arrows) and inflammation in adjacent ischioanal fat

intestinal communication of fistula [8]. Modified X-ray fistulography, on the other hand, has been found to be more useful than the conventional one. Though there are no published reports on Deshpande's technique, but in a study comparing the accuracy of anal endosonography with that of modified fistulography, a similar technique was adopted using Foley's catheter into the rectum and metal ring close to the anus to serve as the marker. Modified fistulography was able to identify internal openings in $74.2 \%$ cases, secondary tracks in 91.8\% cases, and abscesses in $87.8 \%$ cases compared to $79 \%, 98 \%$, and $92.9 \%$ accuracy of anal endosonography, respectively [41]. Apart from some of the studies, most of them have suggested that fistulography has a limited role in fistula imaging and is not in routine practice. As mentioned earlier, CT is also not much useful in depicting the relative anatomy of fistulous tracks due to its poor tissue resolution in comparison to MRI but the use

Table 1 St. James's University Hospital MR imaging classification of fistula in ano [30]

\begin{tabular}{ll}
\hline Grades & Description \\
\hline 0 & Normal appearance on MR imaging \\
1 & Simple linear intersphincteric fistula \\
2 & Intersphincteric fistula with intersphincteric abscess or secondary fistulous track \\
3 & Transsphincteric fistula \\
4 & Transsphincteric fistula with abscess or secondary track within the ischiorectal fossa \\
5 & Supralevator and translevator disease \\
\hline
\end{tabular}


of CT fistulography with multidetector CT units having the capability of isotropic voxels and multiplanar imaging has shown good results. Soker et al. (2016) compared the efficacy of MRI with CT fistulography using 16-channel multidetector CT unit in 41 patients and reported the accuracy of $68.2 \%, 73.1 \%$, and $85.3 \%$ when compared with surgical findings for the location of the internal opening, classification of the primary track, and presence of secondary extensions with MRI showing the respective accuracies to be $85.3 \%, 92.7 \%$, and $87.8 \%$ [42]. Thus, it can be recommended that thin slice spiral CT imaging with fistulography may be referred for assessment of fistula anatomy in cases where MRI is not available or not accessible owing to its cost or is contraindicated [8].

Anal endosonography is a rapid, non- or minimal invasive imaging technique which provides high-resolution images of the anal canal and the adjacent structures and thus may provide the detailed fistula anatomy with respect to the sphincter complex, levator plates, and associated potential spaces. Various studies have revealed the diagnostic accuracy of anal endosonography to be 6394\% for primary tracks and $93 \%$ for locating the internal opening [32]. 3D technology has improved the diagnostic accuracy of endosonography over $2 \mathrm{D}$ imaging as the accuracies for primary tracks, secondary tracks, and internal openings have improved from $89.4 \%, 83.3 \%$, and $87.9 \%$ for $2 \mathrm{D}$ imaging to $98.5 \%, 98.5 \%$, and $96.4 \%$, respectively, for 3D technique [43]. Some studies have also evaluated transperineal ultrasonography (TPUS) in the diagnosis of perianal fistula and compared it with EUS or TRUS. While Maconi et al. showed that TPUS has a positive predictive value of $86.5 \%$ and sensitivity of 84.9\% when compared to EUS in a correct classification and detection of fistula-in-ano [44], Domkundwar and Shinagare reported positive predictive values of $90 \%$ and $85 \%$ and sensitivities of $100 \%$ and $96 \%$ for detection of fistula tracks and the internal opening, respectively [45]. Compared to surgical findings, Zbar et al. showed that the sensitivity of TPUS was the same as that of EUS for detection of transsphincteric and extrasphincteric fistula $(100 \%)$, more in the detection of internal opening $(90 \%$ vs $85 \%)$ and lower than EUS in the detection of associated abscesses (63.6\% vs $81.8 \%$ ) [46]. Moreover, a recent meta-analysis on TPUS for perianal fistulas and abscesses has shown the pooled sensitivities of $98 \%, 91 \%$, $86 \%$, and $92 \%$ in the detection of tracks, internal openings, abscesses, and classification of fistula, respectively [47]. Based on these studies, TPUS is regarded as a simple, cheap, non-invasive, portable, and rapid tool with comparable accuracy to EUS or MRI for diagnosis of perianal fistulas and abscess and hence is recommended as the first-line imaging tool for primary screening of cases, especially in settings where EUS or MRI are not available or are contraindicated like anal stenosis, claustrophobia, and metal implants [44-47]. In addition, the complementary use of TPUS may also help in overcoming the limitation of the limited field of vision with EUS [48]. However, in comparison with TPUS, anal endosonography offers the advantage of imaging in a more surgically relevant plane with better differentiation between sphincters and other structures and the added capability of reconstruction of images in desirable planes when the $3 \mathrm{D}$ technique is used; this is probably the reason that TPUS is still not a recommended imaging modality by authoritative organizations for anal fistulas [7, 49].

MRI is usually considered more accurate than TRUS in the evaluation of anal fistulas and has been recommended as the imaging modality of choice for complex and recurrent fistulas [8]. The accuracies reported for body coil imaging for primary and secondary tracks have been as high as $88 \%$ and $91 \%$, respectively [21, 50, 51], while the accuracy for endoanal coil, which offers better spatial resolution, rose to $93 \%$ for primary track classification [32]. However, MR imaging with endoanal coil has got some specific disadvantages of limited availability, limited field of view in addition to patient's discomfort which may lead to suboptimal imaging due to patient's movement. It is also difficult to be placed in cases of stenosis and pain [12, 32]. External surface phased-array coils are a good alternative with high resolution than body coils and a greater field of view than endoluminal coils. However, various studies comparing the imaging with these coils have found varying results like endoluminal coil found superior in one study and body coil or external coil in other studies [12]. deSouza et al. (1998) while comparing the endoluminal coil to external phased-array coils found endoluminal coils to be superior for internal opening and primary track but external coil to be better for secondary tracks [52]. In a recent study with phased-array surface coil MRI, accuracies for the primary track, secondary track, and internal openings have been reported to be $94.2 \%$, $98.5 \%$, and $98.9 \%$, respectively. The sensitivity and specificity for abscesses were $100 \%$. A simultaneous comparison of T2W TSE (turbo spin echo) and post-contrast T1W TSE sequences revealed the latter to be more sensitive but the former to be more specific for internal opening and secondary tracks [53]. In another prospective study, apart from showing a high sensitivity and specificity for diagnosing fistula track (98.6\% and $99.7 \%)$ and identification of internal opening (97.7\% and 98.6\%), MRI also added significant information in $46.7 \%$ cases regarding parameters of complexity, thus establishing its role as an important pre-operative imaging tool for fistula-in-ano [54]. Emerging technical advances in sequences like DW imaging and subtraction MR fistulography have also offered great promises to aid in diagnosis. DW MRI has shown high sensitivity and 
specificity in the detection of fistula and abscesses [36]. Studies by Hori et al. and Cavusoglu et al. have shown statistically significant improvement in diagnostic accuracy, sensitivity, specificity, and predictive values of T2W MRI in combination with DW imaging, thereby establishing its added value in the diagnosis of fistula-in-ano $[23,35]$. Similarly, Schaefer et al. have shown that the depiction of fistula in relation to surrounding structures is better on digital subtraction MR fistulography [34]. A comparison of anal endosonography with MR imaging in anal fistula evaluation has also led to varying results. In some studies, MR imaging has been found to be superior to anal endosonography $[55,56]$ while in others, results of EUS proved to be slightly better than MRI [57]. The meta-analysis done by Siddiqui et al. (2012) to assess the diagnostic accuracy of anal endosonography and MRI found both to be equally sensitive (87\%) for assessment of perianal fistula; however, the specificity was more for MRI (69\%) than EUS (43\%) though both values were poor [58]. In totality, the general consensus considers MRI as superior to EUS, but EUS has got one important advantage of its direct use in intraoperative settings to directly assist surgical exploration which is not possible with MRI.

\section{Conclusion}

Complex and recurrent fistula in ano should undergo a preoperative imaging for a better understanding of the nature and course of the disease to reduce the chances of recurrence. The selection of imaging modality depends upon multiple factors like the characteristic of the disease and the patient, the advantage of one modality over other, surgeon's preference, cost and availability of the modality, and the expertise of the examiner. The use of radiography and CT scanning is no longer preferred unless in certain circumstances. Though MRI is the recommended choice for imaging fistula in ano, 3D EUS is an emerging modality which has shown comparable results and may be preferred owing to its rapidity and easier availability than MRI.

\section{Abbreviations \\ 2D: Two-dimensional; 3D: Three-dimensional; ADC: Apparent diffusion coefficient; CT: Computed tomography; DE3D: Dual echo three-dimensional; DW: Diffusion-weighted; EUS: Endoanal ultrasonography; FS: Fat-suppressed/ saturated; MRI: Magnetic resonance imaging; T1W: T1-weighted; T2W: T2- weighted; TE: Echo time; TR: Repetition time; TRUS: Transrectal ultrasonography; TSE: Turbo spin echo}

\section{Acknowledgements}

Not applicable

\section{Authors' contributions}

AS and MS conceptualized the idea and design of the article. AS and PY contributed to drafting the manuscript. MS and AV contributed to revising the manuscript critically for important intellectual content. The authors have read and approved the final version of the manuscript.

\section{Authors' information}

MS has been the founder coordinator of the National Resource Center on Ksharasutra Therapy for the treatment of fistula in ano by ksharasutra, the
Ayurvedic medicated seton, at the Department of Shalya Tantra, Faculty of Ayurveda, Institute of Medical Sciences at Banaras Hindu University, Varanasi, India, for the treatment of fistula in ano with over 35 years of experience in the field of proctology. AS and PY are working in the same department while AV is a Professor in the Department of Radiodiagnosis and Imaging at the same institute.

Funding

This research did not receive any grant from any of the funding agencies.

Availability of data and materials

Not applicable

Ethics approval and consent to participate

Not applicable

Consent for publication

Not applicable

\section{Competing interests}

The authors declare that they have no competing interests.

\section{Author details}

${ }^{1}$ Department of Shalya Tantra, Faculty of Ayurveda, Institute of Medical Sciences, Banaras Hindu University, Varanasi, India. ${ }^{2}$ Department of Radiodiagnosis and Imaging, Institute of Medical Sciences, Banaras Hindu University, Varanasi, India.

Received: 17 April 2020 Accepted: 9 July 2020

Published online: 22 July 2020

\section{References}

1. Ramachandra ML, Garg M (2018) A comparative study in the management of fistula in ano using various modalities. Int Surg J 5(6):2223-2227

2. Sheikh P, Baakza A (2014) Management of fistula-in-ano - the current evidence. Indian J Surg 76(6):482-486

3. Vasilevsky CN, Gordon PH (2007) Benign anorectal: abscess and fistula. In: Wolff BG, Fleshman JW, Beck DE, Pemberton JH, Wexner SD (eds) The ASCR $S$ textbook of colon and rectal surgery. Springer Science \& Business Media, New York, pp 192-202

4. Parks AG, Gordon PH, Hardcastle JD (1976) A classification of fistula in ano. $\mathrm{Br} J$ Surg 63:1-12

5. Steele SR, Kumar R, Feingold DL, Rafferty JL, Buie WD Standards practice task force of the American Society of Colon and Rectal Surgeons (2011) Practice parameters for the management of perianal abscess and fistula-inano. Dis Colon Rectum 54(12):1465-1474

6. American Gastroenterological Association (2003) Medical position statement: perianal Crohn's disease. Gastroenterology 125:1503-1507

7. Vogel JD, Jhonson EK, Morris AM, Paquette IM, Saclarides TJ, Feingold DL, Steele SR The Clinical Practice Guidelines Committee of the American Society of Colon and Rectal Surgeons (2016) Clinical practice guidelines for the management of anorectal abscess, fistula in ano and rectovaginal fistula. Dis Colon Rectum 59(12):1117-1133

8. Williams JG, Farrands PA, Williams AB, Taylor BA, Luniss PJ, Sagar PM, Varma JS, George BD (2007) The treatment of anal fistula: ACPGBI Position Statement. Colorectal Dis 9(Suppl. 4):18-50

9. Sahu M (2015) A Manual on fistula in ano and ksharasutra therapy. National Resource Center on Ksharasutra Therapy, Varanasi, pp 73-74

10. Tripathi N, Chavan S, Bendre M, Sharma V (2019) Comparative study of MRI fistulogram and X-ray fistulography with operative findings in fistula in ano. Int Surg J 6(5):1704-1709

11. Williams NS, O'Connell PR, McCaskie AW (eds) (2018) Bailey \& Love's short practice of surgery. 27th edn. CRC Press, Taylor \& Francis Group, Florida. p195.

12. Halligan S, Stoker J (2006) Imaging of fistula in ano. Radiology 239(1):18-33

13. Sofic A, Beslic S, Sehovic N, Caluk J, Sofic D (2010) MRI in evaluation of perianal fistulae. Radiol Oncol 44(4):220-227

14. Liang C, Lu Y, Zhao B, Du Y, Wang C, Jiang W (2014) Imaging of anal fistulas: comparison of computed tomographic fistulography and magnetic resonance imaging. Korean J Radiol 15(6):712-723 
15. Law PJ, Bartram Cl (1989) Anal endosonography: technique and normal anatomy. Gastrointest Radiol 14:349-355

16. Kim MJ (2015) Transrectal ultrasonography of anorectal diseases: advantages and disadvantages. Ultrasonography 34:19-31

17. Mashhour AN, Omar HS, Marzouk AS, Raslan MM, Farag A (2015) Evaluation of the role of endoanal ultrasonography in preoperative assessment of perianal fistula. Egypt J Surg 34:122-126

18. Burnett SJD, Bartram Cl (1991) Endosonographic variations in the normal internal anal sphincter. Int J Colorectal Dis 6(1):2-4

19. Rociu E, Stoker J, Eijkemans MJ, Lameris JS (2000) Normal anal sphincter anatomy and age- and sex-related variations at high-spatial-resolution endoanal MR imaging. Radiology 217:395-401

20. Koelbel G, Schmiedl U, Majer MC, Weber P, Jenss H, Keuper K, Hess CF (1989) Diagnosis of fistulae and sinus tracts in patients with Crohn's disease: value of MR imaging. Am J Roentgenol 152:999-1003

21. Lunniss PJ, Armstrong P, Barker PG, Reznek RH, Phillips RKS (1992) Magnetic resonance imaging of anal fistulae. Lancet 340:394-396

22. Bhaya AK, Kumar N (2007) MRI with MR fistulogram for perianal fistula: a successful combination. Clin Gastrointest Magnetom 1:56-59

23. Hori M, Oto A, Orrin S, Suzuki K, Baron RL (2009) Diffusion-weighted MRI: a new tool for the diagnosis of fistula in ano. J Magn Reson Imaging 30(5): 1021-1026

24. Schaefer O, Lohrmann C, Langer M (2003) Digital subtraction MR fistulography: new diagnostic tool for the detection of fistula in ano. Am J Roentgenol 181:1611-1613

25. Brant WE (2007) Diagnostic imaging methods. In: Brant WE, Helms CA (eds) Fundamentals of diagnostic radiology. 3rd edn. Lippincott Williams \& Wilkins, Philadelphia. p16-17.

26. Stoker J (2009) Anorectal and pelvic floor anatomy. Best Pract Res Clin Gastroenterol 23:463-475

27. deSouza NM, Kmiot WA, Puni R, Hall AS, Burl M, Bartram Cl, Bydder GM (1995) High resolution magnetic resonance imaging of the anal sphincter using an internal coil. Gut 37:284-287

28. deSouza NM, Williams AD, Gilderdale DJ (1999) High resolution magnetic resonance imaging of the anal sphincter using a dedicated endoanal receiver coil. Eur Radiol. 9:436-443

29. Bennett AE (2008) Correlative anatomy of the anus and rectum. Semin Ultrasound CT MRI 29:400-408

30. Morris J, Spencer JA, Ambrose NS (2000) MR imaging classification of perianal fistulas and its implications for patient management. Radiographics 20:623-635

31. de Miguel Criado J, del Salto LG, Rivas PF, del Hoyo LFA, Velasco LG, de las Vacas MIDP, Sanz AGM, Paradela MM, Moreno EF (2012) MR imaging evaluation of perianal fistulas: spectrum of imaging features. Radiographics 32:175-194.

32. Sun MRM, Smith MP, Kane RA (2008) Current techniques in imaging of fistula in ano: three-dimensional endoanal ultrasound and magnetic resonance imaging. Semin Ultrasound CT MR 29(6):454-47

33. Schaefer O, Lohrmann C, Langer M (2004) Assessment of anal fistulas with high-resolution subtraction MR-fistulography: comparison with surgical findings. J Magn Reson Imaging 19:91-98

34. Schaefer O, Lohrmann C, Kreisel W, Rasenack J, Ruf G, Hopt U, Langer M (2005) Differentiation of perianal fistulas with digital subtraction magnetic resonance fistulography. Inflamm Bowel Dis 11(4):383-387

35. Cavusoglu M, Duran S, Sözmen Cilız D, Tufan G, Hatipoglu Cetin HG, Ozsoy A Sakman B (2017) Added value of diffusion-weighted magnetic resonance imaging for the diagnosis of perianal fistula. Diagn Interv Imaging 98:401-408

36. Dohan A, Eveno C, Oprea R, Pautrat K, Placé V, Pocard M, Hoeffel C, Boudiaf M, Soyer P (2014) Diffusion-weighted MR imaging for the diagnosis of abscess complicating fistula-in-ano: preliminary experience. Eur Radiol 24: 2906-2915

37. Yoshizako T, Wada A, Takahara T, Kwee TC, Nakamura M, Uchida K, Hara S, Lujiten PR, Kitagaki H (2012) Diffusion-weighted MRI for evaluating perianal fistula activity: feasibility study. Eur J Radiol 81:2049-2053

38. Proscia N, Jaffe TA, Neville AM, Wang CL, Dale BM, Merkle EM (2010) MRI of the pelvis in women: 3D versus 2D T2-weighted technique. Am J Roentgenol 195(1):254-259

39. Halligan S, Buchanan G (2003) MR imaging of fistula-in-ano. Eur J Radiol 47: 98-107

40. Kuijpers HC, Schulpen T (1985) Fistulography for fistula-in-ano: is it useful? Dis Colon Rectum 28:103-104
41. Pomerri F, Dodi G, Pintacuda G, Amadio L, Muzzio PC (2010) Anal endosonography and fistulography for fistula-in-ano. Radiol Med 115(5): 771-783

42. Soker G, Gulek B, Yilmaz C, Kaya O, Arslan M, Dilek O, Gorur M, Kuscu F, Irkorucu O (2016) The comparison of CT fistulography and MR imaging of perianal fistulae with surgical findings: a case-control study. Abdom Radiol 41:1474-1483

43. Ratto C, Grillo E, Parello A, Costamagna G, Doglietto GB (2005) Endoanal ultrasound-guided surgery for anal fistula. Endoscopy 37:722-728

44. Maconi G, Ardizzone S, Greco S, Radice E, Bezzio C, Porro GB (2007) Transperineal ultrasound in the detection of perianal and rectovaginal fistulae in Crohn's disease. Am J Gastroenterol 102:2214-2219

45. Domkundwar SV, Shinagare AB (2007) Role of transcutaneous perianal ultrasonography in evaluation of fistulas in ano. J Ultrasound Med 26:29-36

46. Zbar AP, Oyetunji RO, Gill R (2006) Transperineal versus hydrogen peroxide enhanced endoanal ultrasonography in never operated and recurrent cryptogenic fistula-in-ano: a pilot study. Tech Coloproctol 10:297-302

47. Maconi G, Greco MT, Asthana AK (2017) Transperineal ultrasound for perianal fistulas and abscesses - a systematic review and meta-analysis. Ultraschall in Med 38:265-272

48. Youssef AT (2015) Imaging classification of perianal fistula using the ultrasound. J Gastroenterol Hepatol Res 4(6):1653-1659

49. Williams G, Williams A, Tozer P, Phillips R, Ahmad A, Jayne D, MaxwellArmstrong C (2018) The treatment of anal fistula: second ACPGBI Position Statement. Colorectal Dis 20(Suppl. 3):5-31

50. Barker PG, Lunniss PJ, Armstrong P, Reznek RH, Cottam K, Phillips RK (1994) Magnetic resonance imaging of fistula-in-ano: technique, interpretation and accuracy. Clin Radiol 49:7-13

51. Spencer JA, Ward J, Ambrose NS (1998) Dynamic contrast-enhanced MR imaging of perianal fistulae. Clin Radiol 53:96-104

52. deSouza NM, Gilderdale DJ, Coutts GA, Puni R, Steiner RE (1998) MRI of fistula-in-ano: a comparison of endoanal coil with external phased array coil techniques. J Comput Assist Tomogr 22:357-363

53. Vo D, Phan C, Nguyen L, Le H, Nguyen T, Pham H (2019) The role of magnetic resonance imaging in the preoperative evaluation of anal fistulas. Sci Rep 9:17947

54. Garg P, Singh P, Kaur B (2017) Magnetic Resonance Imaging (MRI): operative findings correlation in 229 fistula-in-ano patients. World J Surg 41:1618-1624

55. Hussain SM, Stoker J, Schouten WR, Hop WC, Lameris JS (1996) Fistula in ano: endoanal sonography versus endoanal MR imaging in classification. Radiology 200:475-481

56. Maier AG, Funovics MA, Kreuzer SH, Herbst F, Wunderlich M, Teleky BK, Mittlbock M, Schima W, Lechner GL (2001) Evaluation of perianal sepsis: comparison of anal endosonography and magnetic resonance imaging. J Magn Reson Imaging 14:254-260

57. Schwartz DA, Wiersema MJ, Dudiak KM, Fletcher JG, Clain JE, Tremaine WJ, Zinsmeister AR, Norton ID et al (2001) A comparison of endoscopic ultrasound, magnetic resonance imaging and examination under anesthesia for evaluation of Crohn's perianal fistulas. Gastroenterology 121:1064-1072

58. Siddiqui MR, Ashrafian H, Tozer P, Daulatzai N, Burling D, Hart A, Athenasiou T, Phillips RK (2012) A diagnostic accuracy meta-analysis of endoanal ultrasound and MRI for perianal fistula assessment. Dis Colon Rectum 55: $576-585$

\section{Publisher's Note}

Springer Nature remains neutral with regard to jurisdictional claims in published maps and institutional affiliations. 